\title{
Comparative Effect of Physicomechanical and Biomolecular Cues on Zone-Specific Chondrogenic Differentiation of Mesenchymal Stem Cells
}

\author{
Seyedsina Moeinzadeh, Seyed Ramin Pajoum Shariati, Esmaiel Jabbari \\ The first and second authors contributed equally to this manuscript \\ Biomimetic Materials and Tissue Engineering Laboratory \\ Department of Chemical Engineering \\ University of South Carolina, Columbia, SC 29208, USA
}

\section{Submitted to}

\section{BIOMATERIALS}

\section{Corresponding author:}

Esmaiel Jabbari, Ph.D.

Full Professor of Chemical and Biomedical Engineering

Department of Chemical Engineering

Swearingen Engineering Center, Rm 2C11

University of South Carolina

Columbia, SC 29208

Tel: $\quad$ (803) 777-8022

Fax: (803) 777-0973

E-mail: jabbari@cec.sc.edu 
ABSTRACT Current tissue engineering approaches to regeneration of articular cartilage rarely restore the tissue to its normal state because the generated tissue lacks the intricate zonal organization of the native cartilage. Zonal regeneration of articular cartilage is hampered by the lack of knowledge for the relation between physical, mechanical, and biomolecular cues and zone-specific chondrogenic differentiation of progenitor cells. This work investigated in 3D the effect of TGF- $\beta 1$, zone-specific growth factors, optimum matrix stiffness, and adding nanofibers on the expression of chondrogenic markers specific to the superficial, middle, and calcified zones of articular cartilage by the differentiating human mesenchymal stem cells (hMSCs). Growth factors included BMP-7, IGF-1, and hydroxyapatite (HA) for the superficial, middle, and calcified zones, respectively; optimum matrix stiffness was $80 \mathrm{kPa}, 2.1 \mathrm{MPa}$, and 320 MPa; and nanofibers were aligned horizontal, random, and perpendicular to the gel surface. hMSCs with zone-specific cell densities were encapsulated in engineered hydrogels and cultured with or without TGF- $\beta 1$, zone-specific growth factor, optimum matrix modulus, and fiber addition and cultured in basic chondrogenic medium. The expression of encapsulated cells was measured by mRNA, protein, and biochemical analysis. Results indicated that zone-specific matrix stiffness had a dominating effect on chondrogenic differentiation of hMSCs to the superficial and calcified zone phenotypes. Addition of aligned nanofibers parallel to the direction of gel surface significantly enhanced expression of $\mathrm{Col}$ II in the superficial zone chondrogenic differentiation of hMSCs. Conversely, biomolecular factor IGF-1 in combination with TGF- $\beta 1$ had a dominating effect on the middle zone chondrogenic differentiation of hMSCs. Results of this work could potentially lead to the development of multilayer grafts mimicking the zonal organization of articular cartilage.

Keywords: articular cartilage, human MSC, chondrogenesis, zonal cell differentiation, matrix stiffness, nanofiber, TGF- $\beta 1$, BMP-7, IGF-1

\section{Introduction}

During articular cartilage development, mesenchymal stem cells (MSCs) condense in morphologically distinct zones that reflect the spatiotemporal gradient of chondrogenic signaling factors [1]. The differentiated cells form distinct zones, namely, superficial zone for lubrication, middle/deep zone for compressive strength and resisting deformation, and calcified zone for load transmission to the underlying bone tissue [2- 
4]. Each zone is maintained by a unique combination of cellular, biomolecular, mechanical, and physical factors. Osteoarthritis (OA) or degenerative joint disease affects 27M Americans with joint pain and disability [5]. Current treatment methods such as autograft transfer or autologous chondrocyte transplantation rarely restore the tissue to its normal state [6]. There is a need for engineered grafts that recreate the zonal organization of articular cartilage for treating full-thickness articular cartilage defects such as those in advanced OA.

Zonal organization of articular cartilage during development is formed by controlling the secretion and spatial distribution of transforming growth factor- $\beta$ (TGF$\beta$ ), bone morphogenetic protein (BMP), and insulin growth factor (IGF) family of growth factors [7], which results in $450 \%$ increase in tensile and $180 \%$ increase in compressive modulus with depth from the articular surface [8]. The outermost superficial zone is maintained by TGF- $\beta 1$ and BMP-7 signaling, a relatively low matrix stiffness (high compliance, $80 \mathrm{kPa}$ ), and collagen fibrils oriented parallel to the articulating surface [9]. Chondrocytes in the superficial zone express pre-chondrogenic marker Sox-9 and superficial zone protein (SZP) for joint lubrication [3,9]. The middle zone is maintained by TGF- $\beta 1$ and IGF-1 signaling, a matrix stiffness much higher than the superficial zone (2.1 MPa), and collagen fibrils with random alignment [10,11]. Prehypertrophic chondrocytes in the middle zone highly express aggrecan (AGC), glycosaminoglycans (GAG), and collagen type II (Col II) [12,13]. Hypertrophic chondrocytes in the calcified zone are maintained by TGF- $\beta 1$ signaling, high matrix stiffness $(320 \mathrm{MPa})$, and collagen fibrils oriented perpendicular to the articulating surface [14]. Chondrocytes in the calcified zone express hypertrophic markers alkaline phosphatase (ALP) and collagen type X ( $\mathrm{Col} X)$ [13].

In mature articular cartilage tissue, matrix stiffness increases sharply from $80 \mathrm{kPa}$ in the superficial zone to $2.1 \mathrm{MPa}$ in the middle zone and $320 \mathrm{MPa}$ in the calcified zone $[15,16]$. Concurrent with increase in matrix stiffness, orientation of the collagen fibrils changes from parallel to the articulating surface in the superficial zone to random and perpendicular in the middle and calcified zones, respectively [13,17]. In addition to those gradients, the optimum TGF- $\beta 1$ loading increases from $3 \mathrm{ng} / \mathrm{mL}$ in the superficial zone to $30 \mathrm{ng} / \mathrm{mL}$ in the middle and calcified zones $[9,18]$. Further, the expression of BMP-7 [9] and IGF-1 [19] is restricted to the superficial and middle zones, respectively, 
whereas the secretion of hydroxyapatite (HA) by hypertrophic chondrocytes further stimulates mineralization in the calcified zone [20].

We recently demonstrated using a developmentally inspired approach that the combination of TGF- $\beta 1$ as a master regulator of chondrogenesis and zone-specific growth factor, matrix stiffness, and nanofiber orientation led to zone-specific chondrogenic differentiation of encapsulated human mesenchymal stem cells (hMSCs) and expression of corresponding zone-specific markers [18] for the superficial, middle, and calcified zones. The effects of biomolecular factors like TGF- $\beta 1$, BMP-7, IGF-1, and HA, addition of nanofibers and their orientation, and mechanical stiffness on chondrogenic differentiation of MSCs and chondroprogenitor cells have been investigated extensively in the past [20-22]. However, independent effect of the above factors on differentiation of encapsulated MSCs to zone-specific chondrocyte phenotypes of articular cartilage has not been investigated. This work investigated for the first time the effect of TGF- $\beta 1$, zone-specific growth factors (BMP-7 for superficial, IGF-1 for middle, and HA for calcified zone), optimum matrix compressive modulus (80 $\mathrm{kPa}$ for superficial, 2.1 MPa for middle, and $320 \mathrm{MPa}$ for calcified zone), and nanofibers (horizontal for superficial, random for middle, and perpendicular to the articulating surface for calcified zone) on zone-specific chondrogenic differentiation of hMSCs. An engineered hydrogel based on star acrylate-terminated lactide-chain-extended polyethylene glycol macromer (SPELA) with tunable modulus and degradation time was used for hMSC encapsulation.

\section{Materials \& methods}

\subsection{Materials}

Polyethylene glycol (PEG) with nominal molecular weight (MW) of $4.6 \mathrm{kDa}$ was received from Acros Organics (Fairfield, OH). Poly(DL-lactide) (PLA) with MW of 95 $\mathrm{kDa}$ was received from Durect (Birmingham, AL). Photoinitiator 4-(2-hydroxyethoxy) phenyl-(2-hydroxy-2-propyl) ketone (Irgacure 2959) was received from CIBA (Tarrytown, NY). Hydroxyapatite (HA) nanoparticles with long axis of $80 \mathrm{~nm}$ and aspect ratio of 4 were received from Berkeley Advanced Biomaterials (Berkeley, CA) [23]. All Fmoc-protected amino acids, the Rink Amide NovaGel ${ }^{\mathrm{m}}$ resin and hydroxybenzotriazole (HOBt) were purchased from EMD Biosciences (San Diego, CA).
1,1,1,3,3,3-hexafluoro-2-propanol
(HFIP),
$\mathrm{N}, \mathrm{N}$-dimethylformamide
(DMF), 
dichloromethane (DCM), 4-dimethylaminopyridine (DMAP), diisopropylcarbodiimide (DIC), triisopropylsilane (TIPS), trifluoroacetic acid (TFA), hexane and diethyl ether were received from Acros. Calcium hydride, 4,6-diamidino-2-phenylindole (DAPI), paraformaldehyde, triethylamine (TEA), penicillin G, insulin, papain, dithiothreitol, EDTA and streptomycin were received from Sigma-Aldrich (St. Louis, MO). Spectro/Por dialysis tube (MW cutoff $3.5 \mathrm{kDa}$ ) was from Spectrum Laboratories (Rancho Dominquez, CA). DCM solvent was purified by distillation over calcium hydride. All other solvents were reagent grade and used as received. Human mesenchymal stem cells (hMSCs) with high expression of CD105, CD166, CD29, and CD44 and low expression of CD14, CD34 and CD45 markers, were received from Lonza (Allendale, NJ). According to the supplier, the bone marrow was harvested from the posterior iliac crest of one donor (normal, Caucasian, male, 38 years old). Human chondrocytes with $90 \%$ positive staining for Alcian blue were received from Lonza. According to the supplier, chondrocytes were isolated from the hyaline cartilage in the knee of one donor (normal, Caucasian, male, 50 years old). Transforming growth factor$\beta 1$ (TGF- $\beta 1$ ) and Insulin Growth Factor-1 (IGF-1) were purchased from Lonza (Allendale, NJ). Bone morphogenetic protein-7 (BMP-7) and Bovine serum albumin (BSA) were received from Novus (Littleton, $\mathrm{CO}$ ) and Jackson ImmunoResearch (West Grove, PA), respectively. Iodoacetic acid was purchased from Fisher Scientific (Rockford, IL). DMEM cell culture medium, Dulbecco's phosphate-buffer saline (PBS), fetal bovine serum (FBS), trypsin-EDTA, Quant-it Pico-Green dsDNA reagent kit and Alexa Fluor 594 Phalloidin were received from Invitrogen (Carlsbad, CA). All primary and secondary antibodies, luminol reagent and Blotto blocking solution were received from Santa Cruz Biotechnology (Dallas, TX). All forward and reverse primers were synthesized by Integrated DNA Technologies (Coralville, IA).

\section{Synthesis of fiber reinforced hydrogels}

SPELA macromonomer was synthesized by ring-opening chain extension of PEG with a short lactide at each chain-end followed by termination with an acrylate group as we described previously [24,25] (see Figure 1 for structure). Acrylamide-terminated glycine-arginine-glycine-aspartic acid peptide (Ac-GRGD) was synthesized on Rink Amide NovaGel ${ }^{\mathrm{TM}}$ resin in the solid phase as we previously described [26]. Random and aligned PLA nanofiber microsheets were generated by electrospinning from $10 \mathrm{wt} \%$ solution of PLA in HFIP as we previously described [27]. The hydrogel precursor 
solution was prepared by mixing initiator solution ( $5 \mathrm{mg}$ initiator in $1 \mathrm{~mL}$ PBS) with the solution of SPELA macromonomer and Ac-GRGD cell-adhesive peptide in PBS. The hydrogel precursor solution (with or without cells and nanofibers) was crosslinked by ultraviolet (UV) polymerization with an Omni Cure Series 1500 UV illumination system for 30 seconds as we previously described [18]. SPELA10, SPELA7.5 and SPELA5 gels with lactide to PEG molar feed ratio of 10, 7.5 and 5, respectively, with mass loss of $47 \%$, $38 \%$, and $28 \%$ after 21 days in $\mathrm{PBS}$ at $37^{\circ} \mathrm{C}$ for the gels simulating the superficial, middle, and calcified zones of articular cartilage, respectively [28] (Table 1). Compressive moduli of the superficial, middle and calcified zones were simulated with the following fiber-reinforced hydrogels: $15 \mathrm{wt} \%$ SPELA10 and $4 \mathrm{wt} \%$ (by the gel weight) PLA nanofibers oriented parallel with respect to surface of the disk-shape gel for the superficial zone; $50 \mathrm{wt} \%$ SPELA7.5 with $4 \mathrm{wt} \%$ randomly-oriented fibers for the middle zone; and $35 \mathrm{wt} \%$ SPELA5 with $60 \mathrm{wt} \%$ perpendicularly-oriented fibers for the calcified zone (Figure 1). Addition of nanofibers to the superficial and middle zones did not significantly change their modulus in perpendicular direction with respect to the gel surface whereas SPELA5 gel had to be reinforced with nanofibers to reach the required $320 \mathrm{MPa}$ modulus of the calcified zone. The synthetic process to generate hydrogel constructs for simulating the superficial, middle, and calcified zones of articular cartilage is shown in Figure 1. For the superficial zone of articular cartilage, aligned fiber microsheets were dip-coated in SPELA10 gel precursor solution, laminated to simulate the horizontal orientation of the collagen fibers with respect to the chondral surface, and UV crosslinked. For the middle zone, randomly-oriented fiber sheets were cut into small pieces, randomly dispersed in SPELA7.5 precursor solution and crosslinked. For the calcified zone, aligned fiber sheets were dip-coated in SPELA5 precursor solution, wrapped around a needle to simulate the vertical orientation of the fibers with respect to the chondral surface, and crosslinked [18]. Compressive modulus (E) of the hydrogels was measured with an AR2000 rheometer (TA Instruments, New Castle, DE) as we described previously [18].

\section{Cell encapsulation in hydrogels}

hMSCs (passage 3-5) were cultured at a density of 5000 cells $/ \mathrm{cm}^{2}$ in a high glucose DMEM medium supplemented with 10\% FBS, $100 \mathrm{U} / \mathrm{mL}$ penicillin $\mathrm{G}$ and $100 \mu \mathrm{g} / \mathrm{mL}$ streptomycin (basal medium) as described [18]. Fiber microsheets were sterilized by incubation in PBS containing 10,000 $\mathrm{U} / \mathrm{mL}$ penicillin $\mathrm{G}, 10,000 \mu \mathrm{g} / \mathrm{mL}$ streptomycin, 
and $250 \mu \mathrm{g} / \mathrm{mL}$ amphotericin B overnight followed by washing in sterile PBS as described [18]. Hydrogel compositions, fiber loading, in vitro gel degradation, gel compressive modulus, growth factor concentration in the medium, and cell density for hydrogel constructs simulating the the superficial, middle, and calcified zones of articular cartilage are given in Table 1.

Table 1. Gel composition, nanofiber loading, in vitro gel degradation (mass loss), gel compressive modulus, growth factor concentrations, and hMSC cell density for hydrogel constructs simulating the superficial, middle, and calcified zones of articular cartilage.

\begin{tabular}{|c|c|c|c|c|c|c|}
\hline $\begin{array}{l}\text { Simulated } \\
\text { cartilage } \\
\text { zone }\end{array}$ & $\begin{array}{c}\text { Gel } \\
\text { composition }\end{array}$ & $\begin{array}{c}\text { Fiber } \\
\text { orientation \& } \\
\text { loading (wt. } \\
\% \text { ) }\end{array}$ & $\begin{array}{c}\text { In-vitro } \\
\text { Mass loss } \\
\text { after } 21 \text { days }\end{array}$ & $\begin{array}{l}\text { Matrix } \\
\text { modulus }\end{array}$ & Growth factors & $\begin{array}{c}\text { Cell } \\
\text { density } \\
(\text { Cells } / \mathrm{ml})\end{array}$ \\
\hline Superficial & $\begin{array}{l}\text { SPELA10 } \\
(15 \%)\end{array}$ & $\begin{array}{c}\text { Horizontal } \\
4 \%\end{array}$ & $47 \%$ & $80 \mathrm{KPa}$ & $\begin{array}{l}\text { TGF- } \beta 1(3 \mathrm{ng} / \mathrm{ml}) \\
\text { BMP-7 }(100 \mathrm{ng} / \mathrm{ml})\end{array}$ & $60 \times 10^{6}$ \\
\hline Middle & $\begin{array}{l}\text { SPELA7.5 } \\
\quad(50 \%)\end{array}$ & $\begin{array}{l}\text { Random } \\
4 \%\end{array}$ & $38 \%$ & $2.1 \mathrm{MPa}$ & $\begin{array}{l}\text { TGF- } \beta 1(30 \mathrm{ng} / \mathrm{ml}) \\
\text { IGF-7 }(100 \mathrm{ng} / \mathrm{ml})\end{array}$ & $20 \times 10^{\prime}$ \\
\hline Calcified & $\begin{array}{l}\text { SPELA5 } \\
(35 \%)\end{array}$ & $\begin{array}{l}\text { Vertical } \\
60 \%\end{array}$ & $28 \%$ & $320 \mathrm{MPa}$ & $\begin{array}{c}\text { TGF- } \beta 1(30 \mathrm{ng} / \mathrm{ml}) \\
\text { HA }(3 \%)\end{array}$ & $15 \times 10$ \\
\hline
\end{tabular}

To mimic the zonal variation in cell density of adult articular cartilage, cell densities of $60 \times 10^{\circ}, 20 \times 10^{\circ}$ and $15 \times 10^{\circ}$ cells / $\mathrm{mL}$ were used for the superficial, middle and calcified zones, respectively [29]. hMSCs at densities corresponding to each cartilage zone was suspended in $100 \mu \mathrm{L}$ DMEM. Next, the cell suspension was mixed with the sterile hydrogel precursor solution. Nanofiber microsheets oriented in parallel, random and perpendicular direction with respect to the gel surface for the superficial, middle and calcified zone, respectively, were incorporated in the cell-suspended hydrogel precursor solution as described above (Figure 1). The cell-suspended and fiber-reinforced precursor solutions were UV crosslinked as described above followed by incubation in basal medium for $24 \mathrm{~h}$. Next, the basal medium was replaced with one of the zone specific mediums. Superficial zone medium consisted of basal medium supplemented with $3 \mathrm{ng} / \mathrm{mL}$ TGF- $\beta 1$ and $100 \mathrm{ng} / \mathrm{mL}$ BMP-7; middle zone medium was supplemented with $30 \mathrm{ng} / \mathrm{mL}$ TGF- $\beta 1$ and $100 \mathrm{ng} / \mathrm{mL}$ IGF-1; and the calcified zone medium was supplemented with $30 \mathrm{ng} / \mathrm{mL}$ TGF- $\beta 1$ [18]. Cell culture system simulating the 
superficial zone or "Superficial gel" was defined as $60 \times 10^{\circ}$ cells $/ \mathrm{mL}$ hMSCs encapsulated in a gel with $15 \mathrm{wt} \%$ SPELA10 and $4 \mathrm{wt} \%$ parallel nanofibers and cultured in the superficial zone medium; culture system simulating the middle zone or "Middle gel" was 20x10 cells/mL hMSCs in a gel with $50 \mathrm{wt} \%$ SPELA7.5 and $4 \mathrm{wt} \%$ random fibers and cultured in the middle zone medium; culture system simulating the calcified zone or "Calcified gel" was 15x10' cells/mL hMSCs in a gel with 35 wt $\%$ SPELA5 with $60 \mathrm{wt} \%$ perpendicular fibers and cultured in the calcified zone medium. The cells encapsulated in hydrogels were cultured for up to 21 days. At each time point, the samples were evaluated by biochemical, mRNA, and immunohistochemical analysis for the expression of zone-specific chondrogenic markers. Biochemical analysis included cell number, glycosaminoglycan (GAG) content, alkaline phosphatase (ALP) activity, and total collagen content. Markers for mRNA and protein expression included SOX-9 as the master regulator of chondrogenesis [30], superficial zone protein (SZP) for the superficial zone [9], Collagen type II (Col II) and aggrecan (AGC) as ECM components highly expressed in the middle zone [13], and collagen type $\mathrm{X}(\mathrm{Col} \mathrm{X})$ and ALP as markers of hypertrophic chondrocytes in the calcified zone [12].

hMSCs (day zero), human chondrocytes, and hMSCs in a pellet culture were used as controls groups. Chondrocytes as received were used for the measurement of mRNA and protein expression. For pellet cultures, aliquots of $2.5 \times 10^{5} \mathrm{hMSC}$ in $15 \mathrm{ml}$ tubes were centrifuged at $800 \mathrm{rpm}$ for $5 \mathrm{~min}$ and resuspended in the chondrogenic medium supplemented with $10 \mathrm{ng} / \mathrm{mL}$ TGF- $\beta 1$ for 21 days as described [31]. The chondrogenic medium consisted of DMEM (high-glucose), $100 \mathrm{U} / \mathrm{mL}$ penicillin G, $100 \mu \mathrm{g} / \mathrm{mL}$ streptomycin, ITS premix ( $6 \mu \mathrm{g} / \mathrm{mL}$ insulin, $6 \mu \mathrm{g} / \mathrm{mL}$ transferrin, $6 \mu \mathrm{g} / \mathrm{mL}$ selenium), $1.25 \mathrm{mg} / \mathrm{mL}$ BSA, $1 \mathrm{mM}$ sodium pyruvate, $0.35 \mathrm{mM}$ L-proline, $0.1 \mathrm{mM}$-ascorbic acid2-phosphate, and $100 \mathrm{nM}$ dexamethasone. The chondrogenic mRNA marker expressions for the pellet culture and chondrocytes are compared with the maximum expressions of the simulated gels in the Supplementary Figure S1.

\section{Biochemical analysis and staining}

At each time point (7, 14 and 21 days), the cell-encapsulated gel samples were homogenized in lysis buffer (10 mM Tris supplemented with $0.2 \%$ triton in PBS) and sonicated to rupture the cell membrane. Double-stranded DNA content and ALP activity of the homogenized samples were measured with PicoGreen DNA assay 
(Molecular Probes) and QuantiChrom ALP assay (Bioassay Systems) according to manufacturer's instructions [18]. The measured ALP activity was normalized by dividing to DNA content of the sample as described [18]. Total collagen content of each sample was measured by Sircol assay (Biocolor) according to manufacturer's instructions as we described previously [18]. GAG content of each sample was quantified using dimethylmethylene blue (DMMB) assay as we described previously [18]. The assay was calibrated using reagent blanks and serial dilutions of the standard solution of whale chondroitin sulfate, and normalized to DNA content [13]. The measured GAG content was normalized by dividing to the sample DNA content as described [18]. Whole gel samples were fixed in $4 \%$ formaldehyde and stained with Alcian blue and Alizarin red for visualization of GAG and mineralization, respectively, as described $[13,18]$.

5. $m R N A$ analysis

At each time point, total RNA of the homogenized samples was isolated using Trizol and the genomic DNA was removed using Deoxyribonuclease I (Invitrogen) as described [18,26]. $250 \mathrm{ng}$ of the extracted RNA, quantified with a NanoDrop spectrophotometer (ND-1000, ThermoFisher) was converted to cDNA using Promega reverse transcription system (Madison, WI), and the converted cDNA was amplified by RT-qPCR with SYBR green RealMasterMix (Eppendorf, Hamburg, Germany) using BioRad CXF96 PCR system (Bio-Rad, Hercules, CA) and the appropriate gene specific primers. Primers for zone specific chondrogenic markers were designed and selected by Primer3 web-based software as we described previously [32]. The list of primers sequences is provided in reference [18]. At each time point, the measured mRNA expression of the target genes was normalized against the reference house-keeping gene GAPDH and fold changes were compared to the expression of the same gene to day zero (encapsulated hMSCs, day zero).

\section{Western blot analysis}

Cells in the gel samples were lysed in radioimmunoprecipitation assay (RIPA) buffer with EDTA-free protease inhibitor cocktail (cOmplete, ${ }^{\mathrm{rm}}$ Mini, Roche Life Science, Indianapolis, IN) according to manufacturer's instructions. The proteins in the cell lysate were separated by running the samples through a 7.5\% SDS-PAGE electrophoresis gel (10 $\mu \mathrm{g}$ protein per well) using the Mini-gel system (Bio-Rad). Next, 
the pattern of separated proteins was transferred to a nitrocellulose membrane. After blocking in Blotto solution (Santa Cruz Biotechnology), the membranes were incubated with a mixture of primary antibodies (1:10,000 dilution) in PBS with 5\% dry milk and $0.1 \%$ Tween-20 overnight at $4{ }^{\circ} \mathrm{C}$. The primary antibodies (Santa Cruz Biotechnology) included rabbit anti-human against SZP, Col II, Col X, AGC, and $\beta$-actin. After washing, the membranes were incubated with horseradish peroxidase-conjugated secondary antibodies (1:5000) for $1 \mathrm{~h}$ at ambient conditions. After washing, the membranes were incubated with enhanced luminol-based (ECL) detection reagent (Santa Cruz Biotechnology) and the luminescence was captured using a ChemiDoc MP system (BioRad). The intensity of the antibody-antigen bands was quantified with Image-J software (National Institutes of Health, Bethesda, MD).

\section{Statistical analysis}

All experiments were performed in triplicate and expressed as means \pm standard deviation. Significant differences between groups were calculated using a two-way ANOVA with replication test, followed by a two-tailed Students t-test. P values $<0.05$ were considered statistically significant.

\section{Results}

The effects of TGF- $\beta 1$, zone-specific growth factor, matrix modulus, and fibers on the expression of mRNA and biochemical markers of hMSCs encapsulated in Superficial, Middle, and Calcified gels are shown in Figures 2, 4, 6, and 8, respectively, and protein expressions are shown in Figures 3, 5, 7, and 9. Three control groups were used to evaluate the quality of mRNA and protein expressions. The first control was hMSCs at day zero after encapsulation in the simulated gels with its mRNA marker expression levels shown by a pink diamond in Figures 2, 4, 6, and 8. The second control was as-received human chondrocytes with its mRNA marker expression levels shown by a brown diamond in Figures 2, 4, 6, and 8. The third control was hMSCs in pellet culture with its mRNA expression levels at day 14 shown by a black diamond in Figures $2,4,6$, and 8 . The chondrogenic mRNA marker expressions for the pellet culture and chondrocytes are compared with maximum expressions of the simulated gels as a function of incubation time in Supplementary Figure S1. As for protein expressions of the control groups, the relative SZP, AGC, Col II and Col X protein expressions for 
hMSCs (day zero) were $0.010 \pm 0.005,0.001 \pm 0.001,0.005 \pm 0.001$ and $0.008 \pm 0.003$, respectively; for chondrocytes were $0.950 \pm 0.025,0.587 \pm 0.081,0.960 \pm 0.030$ and $0.079 \pm 0.009$; and for hMSCs in the pellet culture (day 14) were $0.526 \pm 0.075,0.520 \pm 0.064$, $0.326 \pm 0.078$ and $0.930 \pm 0.043$. Results in Figures 2-9 demonstrate that marker expressions of hMSCs encapsulated in the simulated zone-specific gels were within the range for human chondrocytes and pellet-cultured hMSCs.

\subsection{Effect of TGF- $\beta 1$}

The effect of TGF- $\beta 1$ on zonal lineage commitment in chondrogenic differentiation of hMSCs encapsulated in Superficial, Middle, and Calcified gels is shown in Figures 2 and 3. Expression of markers increased with incubation for all time points in all three gels with the exception of Sox-9 and ALP. Sox-9 increased initially, peaked on day 14, then decreased from day 14 to 21 (Figure 2b). ALP expression at the mRNA and protein levels for Calcified gel with no TGF- $\beta 1$ decreased from day 14 to 21 (Figure 2f,i). For the Superficial gel (L1, red), TGF- $\beta 1$ positively affected mRNA (Figure 2a) and protein (Figure 3a) expressions of the superficial marker SZP as well as GAG content (Figure $2 \mathrm{~h}$ ) after 21 days incubation. SZP mRNA and protein expressions increased by 2.9-fold and 1.3-fold, respectively, with addition of TGF- $\beta 1$ after 21 days (Figures $2 \mathrm{a}$ and $3 \mathrm{a}$ ). A slight increase in mRNA expression of chondrogenic markers Sox-9 (Figure 2b) and Col II (Figure 2d) and a slight decrease in expression of hypertrophic marker Col X (Figure $2 \mathrm{e})$ were observed with addition of TGF- $\beta 1$ to Superficial gel for all time points. For Middle gel (L2, blue), TGF- $\beta 1$ positively affected the synthesis of matrix proteins GAG (Figure 2h) and total collagen (Figure 2g) for all time points. Further, except for the expression of hypertrophic markers ALP and Col X (Figures 2e,f), addition of TGF- $\beta 1$ positively affected mRNA and protein expressions of all chondrogenic markers in Middle gel for all time points (Figures 2,3). For example, total collagen content of Middle gel increased by 2.4-fold from day 7 to 21 with addition of TGF- $\beta 1$ (Figure 2g). For Calcified gel (L3, green), TGF- $\beta 1$ positively affected mRNA and protein expressions of the markers of hypertrophic chondrocytes including Col X (Figure 2e; Figures 3d,e) and ALP (Figures 2f,i) as well as total collagen content (Figure 2g) after 21 days. Col X mRNA expression increased by 2.5 -fold (Figure 2e) and Col $X$ relative protein expression increased from 0.26 to 0.46 (Figure 3d) on day 14 after addition of TGF- $\beta 1$ to Calcified gel. Addition of TGF- $\beta 1$ also had a positive effect on AGC expression in 
Calcified gel with 3.5-fold increase in mRNA expression after 21 days (Figure 2c) and 5fold increase in protein expression (Figure 3b) after 14 days. Based on Figure $3 f$, intensity of Alcian blue staining for GAG increased with TGF- $\beta 1$ addition to the simulated gels, and it increased from Superficial to Calcified gel. Intensity of Alizarin red staining for mineralization (Figure $3 \mathrm{~g}$ ) increased with addition of TGF- $\beta 1$ to Calcified gel. To summarize, based on mRNA and protein expressions, TGF- $\beta 1$ had significant positive effect on SZP expression in Superficial gel, positive effect on expression of chondrogenic markers AGC and Col II in Middle gel, and positive effect on expression of hypertrophic marker $\mathrm{Col} \mathrm{X}$ in Calcified gel.

\subsection{Effect of zone-specific growth factors}

The effect of zone-specific growth factors on zonal chondrogenic differentiation of hMSCs encapsulated in Superficial, Middle, and Calcified gels is shown in Figures 4 and 5. Expression of markers increased with incubation for all time points in all three gels with the exception of Sox-9. SZP expression in Superficial gel with BMP-7 at protein and mRNA levels and in Calcified gel with HA at protein level did not change with incubation from day 14 to 21 (Figures 4a and 5a). GAG expression in Calcified gel with HA did not change with incubation time from day 14 to 21 (Figure 4h). For Superficial gel, addition of BMP-7 to TGF- $\beta 1$ positively affected mRNA and protein expressions of superficial zone marker SZP (Figures 4a and 5a). SZP protein expression of Superficial gel with BMP-7 (Figure 5a) was significantly higher than Middle and Calcified gels for all time points. Addition of BMP-7 also positively affected mRNA expression of Sox-9 and AGC as well as protein expression of AGC and Col II. Conversely, BMP-7 negatively affected protein expression of Col X in Superficial gel (Figure $5 \mathrm{~d}, \mathrm{e}$ ). For Middle gel, addition of IGF-1 to TGF- $\beta 1$ significantly increased mRNA expression of chondrogenic markers Sox-9 (Figure 4b), AGC (Figure 4c), and Col II (Figure 4d) as well as protein expression of AGC (Figure 5b) and Col II (Figure 5c). Further, expression of matrix proteins GAG (Figure 4h) and total collagen (Figure 4g) in Middle gel significantly increased with IGF-1 addition for all time points. Conversely, IGF-1 slightly reduced mRNA and protein expressions of SZP in Middle gel (Figure 4a and Figure 5a). For Calcified gel, addition of HA to TGF- $\beta 1$ only increased ALP activity with incubation time (Figure 4i). Further, expression of chondrogenic marker Sox-9 did not change with addition of HA to Calcified gel. Based on Figure 5f, intensity of Alcian blue staining for GAG increased with IGF-1 addition to Superficial gel (second row 
images). Intensity of Alizarin red staining for mineralization (Figure 5g) increased with addition of HA to Calcified gel. To summarize, based on mRNA and protein analysis, zone-specific factor BMP-7 significantly increased expression of SZP in Superficial gel, IGF-1 increased AGC and Col II in Middle gel, but addition of HA did not affect Col X protein expression in Calcified gel.

\subsection{Effect of matrix stiffness}

The effect of matrix stiffness on zonal chondrogenic differentiation of hMSCs encapsulated in Superficial, Middle, and Calcified gels is shown in Figures 6 and 7. Expression of markers increased with incubation for all time points in all three gels with the exception of Sox-9. SZP expression in Superficial gel with optimum modulus at mRNA level and in Calcified gel with optimum modulus at protein level did not change with incubation from day 14 to 21 (Figure 6a and 7a). GAG expression in Calcified gel with optimum modulus did not change with incubation time from day 14 to 21 (Figure 6h). mRNA and protein expressions for the matrix stiffness specific to each zone were compared with the matrix having a modulus representing the average stiffness of articular cartilage or the modulus of middle zone (2.1 MPa) which is the thickest zone of articular cartilage. For Superficial gel, mRNA expression of markers Sox-9 (Figure 6b) and SZP (Figure 6a), and SZP protein expression (Figure 7a) declined sharply as modulus increased from $80 \mathrm{kPa}$ to $2.1 \mathrm{MPa}$ whereas protein expression of markers $\mathrm{Col}$ II (Figures 6d and 7c) and Col X (Figure 6e and Figure 7d) increased. The increase in modulus of Superficial gel from $80 \mathrm{kPa}$ to $2.1 \mathrm{MPa}$ led to 2.7-fold (Figure 6a) and 1.6fold (Figure 7a) decrease in mRNA and protein expression of SZP. At the modulus of 80 $\mathrm{kPa}$, Superficial gel had the highest mRNA and protein expressions of SZP (Figures 6a and 7a) among all gels for all time points. For Calcified gel, mRNA expression of Col X (Figure 6e) and ALP (Figure 6f), ALP activity (Figure 6i), and Col X (Figure 7d) protein expression sharply decreased as modulus was reduced from $320 \mathrm{MPa}$ to $2.1 \mathrm{MPa}$. Conversely, the reduction in modulus of Calcified gel slightly increased total collagen content (Figure 6g) and GAG (Figure 6h). ALP activity of Calcified gel (Figure 6i) with modulus of $320 \mathrm{MPa}$ was at least 5-fold higher than all other gels after 21 days. Based on Figure $7 f$, the optimum matrix modulus did not affect intensity of Alcian blue staining for GAG in Superficial and Calcified gels consistent with the results in Figure 6h. Intensity of Alizarin red staining (Figure 7g) increased sharply in Calcified gel with optimum modulus. To summarize, the change in modulus of Superficial and Calcified 
gels from their respective natural values to the average stiffness of articular cartilage $(2.1 \mathrm{MPa})$ sharply reduced expression of SZP protein in Superficial gel and Col X expression and ALP activity in Calcified gel for all time points.

\subsection{Effect of nanofiber reinforcement}

The effect of fiber reinforcement on zonal chondrogenic differentiation of hMSCs encapsulated in Superficial, Middle, and Calcified gels is shown in Figures 8 and 9. Expression of markers increased with incubation for all time points in all three gels with the exception of Sox-9. SZP expression in Superficial gel with no fibers at mRNA level and in Calcified gel with fibers at protein level did not change with incubation from day 14 to 21 (Figure 8a and 9a). Col X expression at mRNA and protein levels in Superficial gel (with or no fibers) did not change with incubation time from day 14 to 21 (Figure 8e). GAG expression in Calcified gel with fibers did not change with incubation time from day 14 to 21 (Figure 8h). ALP expression at mRNA level in Middle gel with fibers did not change from day 14 to 21 (Figure 8i). Simulation of the calcified zone required a modulus of $320 \mathrm{MPa}$ which was achievable with a relatively high fraction $(60 \%)$ of nanofibers in Calcified gel. As a result, unlike Superficial and Middle gels, effect of matrix modulus and fibers on zonal chondrogenic differentiation of hMSCs could not be investigated independently (see Table 4). Addition of fibers to the Superficial gel sharply increased the expression of all chondrogenic markers except SZP (Figures 8 and 9) including Sox-9, AGC, Col II, and Col X mRNA expressions, total collagen and GAG, and $\mathrm{Col}$ II and Col X protein expressions. Addition of fibers to Middle gel slightly increased expression of chondrogenic markers like total collagen, Col II, GAG, and AGC. For example, total collagen, Col II, and GAG in Middle gel increased by 1.2, 1.25, and 1.2-fold, respectively, after 21 days with fiber addition. Based on Figure 9f, intensity of Alcian blue staining for GAG increased with fiber addition to Superficial gel (first and second images) but GAG staining did not change with fiber addition to Middle gel (third and fourth images). To summarize, addition of fibers significantly enhanced total collagen and Col II in Superficial gel for all time points but it had a slight positive effect on expression of chondrogenic markers in Middle gel.

\section{Discussion}


The data for the effect of optimum matrix modulus, TGF- $\beta 1$, BMP-7, and fiber addition on expression of superficial zone markers (SZP, Sox-9, Col II, total collagen) for hMSCs encapsulated in Superficial gel (red curves in Figures 2-9) are summarized as the percent normalized change in Table 2. The normalized percent change is the net change in a given expression after adding one of the factors (TGF- $\beta 1$, zone-specific growth factor, optimum stiffness or fiber) divided by the largest expression associated with that factor in all experimental groups (Superficial, Middle, and Calcified gels). For example, the normalized \%change in SZP mRNA expression with addition of TGF- $\beta 1$ was calculated by:

$$
\left(\frac{S Z P_{w T G F}-S Z P_{w o T G F}}{S Z P_{M a x}}\right) \times 100
$$

where $S Z P_{w T G F}$ and $S Z P_{w o T G F}$ are SZP mRNA expressions after and before TGF- $\beta 1$ to the culture medium, respectively, and $\mathrm{SZP}_{\mathrm{Max}}$ is the maximum SZP mRNA expression in all experimental groups. The above equation in combination with the raw expression data (mRNA, biochemical, or protein expressions) for the effect of each independent parameter were used to calculate the standard error propagation for the mean values in Tables 2-4 as described [33]. For each expression marker, the mean values and standard deviations corresponding to the four independent variables were compared. The mean value within a column in Tables 2-4 that was statistically higher than the other values in that column (shown in bold) represented the dominating factor among the four independent factors with respect to expression of the specified marker.

Table 2. Effect of physicomechanical (matrix modulus and fiber) and biomolecular cues (TGF- $\beta 1$ and BMP-7) on percent normalized change in expression of superficial zone markers for hMSCs encapsulated in Superficial gel.

\begin{tabular}{|c|c|c|c|c|c|c|}
\hline \multirow{2}{*}{} & \multicolumn{2}{|c|}{ mRNA expression } & \multicolumn{2}{c|}{$\begin{array}{c}\text { Protein } \\
\text { expression }\end{array}$} & $\begin{array}{c}\text { Biochemical } \\
\text { measurement }\end{array}$ \\
\cline { 2 - 7 } & SZP & Sox-9 & Col II & SZP & Col II & total collagen \\
\hline TGF- $\beta 1$ & $11 \pm 8$ & $6 \pm 9$ & $4 \pm 9$ & $12 \pm 5$ & $-3 \pm 10$ & $4 \pm 5$ \\
\hline BMP-7 & $25 \pm 8$ & $\mathbf{2 1} \pm \mathbf{1 0}$ & $4 \pm 9$ & $8 \pm 8$ & $-4 \pm 12$ & $5 \pm 4$ \\
\hline $\begin{array}{c}\text { optimum matrix } \\
\text { modulus }\end{array}$ & $\mathbf{5 1 \pm 7}$ & $\mathbf{2 6} \pm \mathbf{6}$ & $\begin{array}{c}-17 \pm \\
4\end{array}$ & $\mathbf{2 6} \pm \mathbf{7}$ & $-13 \pm 11$ & $-5 \pm 3$ \\
\hline fiber & $16 \pm 9$ & $\mathbf{2 5} \pm \mathbf{8}$ & $\mathbf{4 5} \pm \mathbf{9}$ & $9 \pm 8$ & $\mathbf{2 8} \pm \mathbf{1 2}$ & $\mathbf{3 9} \pm \mathbf{8}$ \\
\hline
\end{tabular}


The expression of SZP marker in compliant Superficial gel increased slightly with TGF- $\beta 1$ addition to the medium. Conversely, TGF- $\beta 1$ did not increase SZP expression in stiff Calcified gel (Figure 2a). Although the beneficial effect of TGF- $\beta 1$ on SZP expression is previously reported [34], the data in Table 2 show the dominating effect of matrix compliance on chondrogenic differentiation of encapsulated hMSCs to the superficial zone phenotype. In the presence of TGF- $\beta 1$, optimum matrix modulus (80 $\mathrm{kPa}$ ) increased SZP mRNA and protein expressions of the encapsulated hMSCs by $51 \%$ and $26 \%$, respectively (Table 2 ).

These results are consistent with previous results on the pattern of SZP expression in response to mechanical stimulation by shear loading of bovine articular cartilage explants with and without inhibition of TGF- $\beta 1$ signaling [35]. Addition of BMP-7 to the medium increased SZP expression of hMSCs in Superficial gel but to a lesser extent compared to matrix modulus (Table 2). Several previous studies have elucidated the role of BMP-7 on superficial zone of articular cartilage and SZP expression [36,37]. For example, there was higher accumulation of SZP in chondrocyte monolayers with addition of BMP-7 to the medium and the effect was more pronounced when TGF- $\beta 1$ was also added [36]. In another study, there was higher SZP accumulation as well as higher expression of Col II, Sox-9, and AGC in synovial-derived MSCs when the medium was supplemented with TGF- $\beta 1$ and BMP-7 [37]. Further, the data in Table 2 show that the optimum matrix stiffness as well as BMP-7 contributed to up-regulation of Sox- 9 by the differentiating hMSCs $(+26 \%$ and $+21 \%$ at the mRNA level) but they had a negative impact on Col II and total collagen expression (-13\% and $-4 \%$ for Col II at the protein level) in Superficial gel. Sox-9 is a master transcriptional regulator in condensation and chondrogenic differentiation of MSCs [38] and expression of Col II and AGC is upregulated by Sox-9 binding to the TGF- $\beta 1$ effectors SMAD 2/3 in the nuclear compartment [39]. Therefore, down-regulation of Col II and total collagen in the encapsulated hMSCs concurrent with Sox-9 upregulation indicates that SMAD 2/3 expression is regulated by the optimum matrix modulus and BMP-7. Indeed, as previously reported, elevated levels of Sox-9 in 3D micromass cultures of mouse mesenchymal cells derived from limb buds did not necessarily increase Col II expression [40].

According to the data in Table 2, and Figures 8 and 9, mRNA and protein expressions of Col II and total collagen content of the encapsulated hMSCs increased 
significantly with addition of aligned nanofibers parallel to the gel surface. Several previous studies have shown that nanoscale morphology of the scaffold affects chondrogenic differentiation and marker expression of MSCs [17,41]. In one report, cultivation of goat MSCs in a scaffold based on electrospun poly(vinyl alcohol) nanofibers increased expression of Col II, AGC, and sox9 as well as GAG content compared to 3D pellet culture [17]. In another report, the expression of sox-9, Col II and AGC of the MSCs encapsulated in a PEG hydrogel increased by incorporating collagen fibers in the gel [41]. The effect of aligned nanofibers in Superficial gel on Col II mRNA $(45 \%)$, protein $(28 \%)$ expressions, and total collagen content $(39 \%)$ was dominant compared to the effect of random fibers in Middle gel (16\% for Col II mRNA, $18 \%$ for Col II protein, $16 \%$ for total collagen expression, Table 3). This dominant effect can be explained by the higher extent of cell adhesion and cell alignment on the aligned nanofibers as well as higher local stiffness of the aligned fibers compared to random fibers [42,43]. In that regard, the adhesion characteristic of MSCs in a fibrous matrix was reported to be more dependent on fiber alignment and local fiber stiffness than the bulk matrix stiffness [42]. According to the results, optimum matrix modulus, TGF- $\beta 1$, and aligned fibers played a pivotal role in chondrogenic differentiation of hMSCs to the superficial zone phenotype. Optimum matrix modulus and TGF- $\beta 1$ synergistically upregulated expression of SZP and Sox-9 whereas aligned nanofibers increased Col II and total collagen content. BMP-7 had a similar affect on SZP and Sox-9 to that of optimum matrix modulus but to a lesser extent.

The data for the effect of TGF- $\beta 1$, IGF-1, and fiber addition on expression of middle zone markers (Sox-9, AGC, GAG, Col II, total collagen) for hMSCs encapsulated in the Middle gel (blue curves in Figures 2-9) are summarized as the percent normalized change in Table 3. The addition of TGF- $\beta 1$ to the medium had a positive effect on the expression Sox-9, AGC, Col II, total collagen, and GAG but only the effect total collagen and AGC was dominant ( $+32 \%$ change, Table 3$)$. Previous results demonstrated the significant effect of TGF- $\beta 1$ on Sox-9, Col II, and AGC expression during chondrogenesis.

Table 3. Effect of physical (matrix modulus and fiber) and biomolecular cues (TGF- $\beta 1$ and IGF-1) on percent normalized change in expression of middle zone markers for hMSCs encapsulated in Middle gel.

\begin{tabular}{|l|l|c|c|}
\hline mRNA expression & $\begin{array}{c}\text { protein } \\
\text { expression }\end{array}$ & $\begin{array}{c}\text { biochemical } \\
\text { measurement }\end{array}$ \\
\hline
\end{tabular}




\begin{tabular}{|c|c|c|c|c|c|c|c|} 
& Sox9 & AGC & Col II & Col II & AGC & total Col & GAG \\
\hline TGF- $\beta 1$ & $10 \pm 6$ & $21 \pm 8$ & $17 \pm 7$ & $10 \pm 3$ & $\mathbf{2 1} \pm \mathbf{2}$ & $\mathbf{3 2} \pm \mathbf{7}$ & $17 \pm 7$ \\
\hline IGF-1 & $20 \pm 9$ & $\mathbf{4 7} \pm \mathbf{1 0}$ & $\mathbf{3 0} \pm \mathbf{6}$ & $\mathbf{2 4} \pm \mathbf{7}$ & $\mathbf{2 5} \pm \mathbf{7}$ & $\mathbf{2 8} \pm \mathbf{4}$ & $22 \pm 7$ \\
\hline $\begin{array}{c}\text { Optimum } \\
\text { matrix modulus }\end{array}$ & NA & NA & NA & NA & NA & NA & NA \\
\hline fiber & $-11 \pm 10$ & $14 \pm 10$ & $16 \pm 11$ & $\mathbf{1 8} \pm \mathbf{5}$ & $7 \pm 8$ & $16 \pm 7$ & $13 \pm 10$ \\
\hline
\end{tabular}

According to a previous report, addition of $5 \mathrm{ng} / \mathrm{mL}$ TGF- $\beta 1$ to the chondrogenic medium upregulated expression of Col II and Sox-9 in adipose-derived stromal cells (ADSCs) [44]. A previous report indicated that TGF- $\beta 1$ and optimum matrix stiffness possess equal chondroinductive effects on murine chondrocytes [45]. Analysis of the data in Figure 6 indicated that matrix modulus (2-320 MPa) did not affect expression of middle zone markers in the encapsulated hMSCs whereas TGF- $\beta 1$ played a significant role in differentiation of hMSCs to the middle zone phenotype (Figure 2). Addition of IGF-1 as well as TGF- $\beta 1$ to the medium significantly increased expression of middle zone markers ( $>25 \%$ change for AGC, Col II, and total collagen) for hMSCs encapsulated in Middle gel (Table 3), consistent with previous reports [46,47]. For example, addition of IGF-1 and TGF- $\beta 1$ to the chondrogenic medium in a previous study significantly increased Col II expression and cartilage matrix synthesis for periosteal-derived MSCs encapsulated in agarose gel [46]. It was also reported that IGF1 acts synergistically with TGF- $\beta 1$ to increase Col II and GAG content in prehypertrophic chondrocytes [10]. Further, upregulation of Col II and downregulation of Col I was reported for hMSCs cultured in chondrogenic medium supplemented with both IGF-1 and TGF- $\beta 3$ compared with TGF- $\beta 3$ alone [47]. According to Table 3, addition of random fibers to Middle gel increased Col II while it decreased Sox-9 expression. Therefore, based on the results, IGF- 1 and TGF- $\beta 1$ played a dominant role in differentiation of encapsulated hMSCs to the middle zone phenotype as compared with matrix modulus or nanofibers.

The data for the effect of TGF- $\beta 1, H A$, and optimum matrix stiffness on the expression of calcified zone markers (Col X and ALP) for hMSCs encapsulated in the calcified gel (green curves in Figures 2-9) are summarized as the percent normalized change in Table 4.

Table 4. Effect of mechanical (matrix modulus+fibers) and biomolecular cues (TGF- $\beta 1$ and HA) on percent normalized change in expression of calcified zone markers for hMSCs encapsulated in Calcified gel. 


\begin{tabular}{|c|c|c|c|c|}
\hline \multirow{2}{*}{} & \multicolumn{2}{|c|}{$\begin{array}{c}\text { mRNA } \\
\text { expression }\end{array}$} & $\begin{array}{c}\text { protein } \\
\text { expression }\end{array}$ & $\begin{array}{c}\text { biochemical } \\
\text { measurement }\end{array}$ \\
\cline { 2 - 5 } & Col X & ALP & Col X & ALP \\
\hline TGF- $\beta 1$ & $33 \pm 7$ & $\mathbf{4 0} \pm \mathbf{1 4}$ & $19 \pm 9$ & $24 \pm 9$ \\
\hline HA & $30 \pm 11$ & $-8 \pm 13$ & $9 \pm 10$ & $27 \pm 11$ \\
\hline $\begin{array}{c}\text { optimum } \\
\text { matrix } \\
\text { modulus+fiber }\end{array}$ & $\mathbf{5 2} \pm \mathbf{8}$ & $\mathbf{4 9} \pm \mathbf{1 1}$ & $14 \pm 7$ & $\mathbf{7 7} \pm \mathbf{8}$ \\
\hline
\end{tabular}

Addition of TGF- $\beta 1$ to the medium significantly affected expression of hypertrophy markers Col X and ALP at mRNA level but the impact was less significant at protein level (19\% for Col X) or biochemical analysis ( $24 \%$ for ALP, Table 4$)$. TGF- $\beta 1$ contributes to chondrogenic differentiation of progenitor cells by upregulating Sox-9 which in turn delayed hypertrophy by inhibiting Runx-2 activation [39]. Expression of Sox-9 was upregulated up to day 14 in Calcified gel with addition of TGF- $\beta 1$ (Figure $2 b$ ) whereas expression of Col X and ALP was upregulated for the entire culture period (Figures 2e,i) which can be explained by the need for the differentiating hMSCs to commit to chondrogenesis prior to undergoing hypertrophy [48]. Addition of HA to Calcified gel increased Col X expression at mRNA level and ALP activity consistent with previously reported results [49]. However, the most dominant factor for expression of hypertrophy markers in hMSCs encapsulated in Calcified gel was the optimum matrix modulus even in the absence of HA. Expression of ALP at mRNA level and by chemical analysis increased by $49 \%$ and $77 \%$, respectively, as the matrix compressive modulus increased from 2.1 MPa to $320 \mathrm{MPa}$ (Table 4). According to a previous study, ALP and Col X expression of MSCs encapsulated in a hyaluronic acid gel increased significantly as the matrix stiffness increased from 0.2 to $54 \mathrm{kPa}$ [50].

The goal of this research was to investigate the role of individual factors in the microenvironment (physical, mechanical, biochemical, and cellular) on chondrogenic differentiation of hMSCs to specific zonal phenotypes (superficial, middle, and calcified) of articular cartilage. The long-term impact of this work will be the integration of Superficial, Middle, and Calcified gels into one construct for regeneration of full-thickness articular cartilage defects.

\section{Conclusion}

In this work, the specific effect of a physical cue (addition of fibers), a mechanical cue (zone-specific matrix modulus), and two biomolecular factors (TGF- $\beta 1$ and a zone- 
specific growth factor) on zone-specific chondrogenic differentiation of encapsulated hMSCs was investigated at mRNA and protein levels and by biochemical measurements. Analysis of the data indicated that the optimum or zone-specific matrix modulus had a dominating effect on differentiation of hMSCs to the superficial zone (0.8 MPa stiffness) and calcified zone (320 MPa stiffness) chondrocyte phenotypes. The addition of aligned nanofibers parallel to the direction of gel surface significantly enhanced expression of Col II in the superficial zone chondrogenic differentiation of encapsulated hMSCs. Conversely, biomolecular factor IGF-1 in combination with TGF$\beta 1$ had a dominating effect on the middle zone chondrogenic differentiation of encapsulated hMSCs.

\section{Acknowledgements}

This work was supported by research grants to E. Jabbari from the United States National Science Foundation under Award Numbers CBET1403545 and IIP150024 and the National Institute of Arthritis and Musculoskeletal and Skin Diseases of the National Institutes of Health under Award Number AR063745. The content is solely the responsibility of the authors and does not necessarily represent the official views of the National Institutes of Health. The authors thank Mr. Danial Barati for assisting in the synthesis of PEG based macromers. 


\section{References}

[1] H. Akiyama, V. Lefebvre, Unraveling the transcriptional regulatory machinery in chondrogenesis, J. Bone Miner. Metabol. 29 (2011) 390-395.

[2] S.P. Grogan, S.F. Duffy, C. Pauli, J.A. Koziol, A.I. Su, D.D. D'Lima, M.K. Lotz, Zone-specific gene expression patterns in articular cartilage, Arthritis Rheum. 65 (2013) 418-28.

[3] F. Las Heras, H.K. Gahunia, K.P. Pritzker, Articular cartilage development: A molecular perspective, Orthop. Clin. North Am. 43 (2012) 155-171.

[4] M. Pacifici, E. Koyama, Y. Shibukawa, C. Wu, Y. Tamamura, M. EnomotoIwamoto, M. Iwamoto, Cellular and molecular mechanisms of synovial joint and articular cartilage formation, Ann. N. Y. Acad. Sci. 1068 (2006) 74-86.

[5] L. Kock, C.C. van Donkelaar, K. Ito, Tissue engineering of functional articular cartilage: The current status, Cell Tissue Res. 347 (2012) 613-27.

[6] B. Mollon, R. Kandel, J. Chahal, J. Theodoropoulos, The clinical status of cartilage tissue regeneration in humans, Osteoarthritis cartilage 21 (2013) 1824-1833.

[7] P. Dy, P. Smits, A. Silvester, A. Penzo-Mendez, B. Dumitriu, Y. Han, C.A. de la Motte, D.M. Kingsley, V. Lefebvre, Synovial joint morphogenesis requires the chondrogenic action of sox 5 and sox6 in growth plate and articular cartilage, Dev. Biol. 341 (2010) 346-359.

[8] J.L. Silverberg, S. Dillavou, L. Bonassar, I. Cohen, Anatomic variation of depthdependent mechanical properties in neonatal bovine articular cartilage, J. Orthop. Res. 31 (2013) 686-691.

[9] J.A. Andrades, S.C. Motaung, P. Jimenez-Palomo, S. Claros, J.M. Lopez-Puerta, J. Becerra, T.M. Schmid, A.H. Reddi, Induction of superficial zone protein (SZP)/lubricin/PRG 4 in muscle-derived mesenchymal stem/progenitor cells by transforming growth factor-beta1 and bone morphogenetic protein-7, Arthritis Res. Ther. 14 (2012) R72.

[10] E. Coates, J.P. Fisher, Gene expression of alginate-embedded chondrocyte subpopulations and their response to exogenous IGF-1 delivery, J. Tissue Eng. Regen. Med. 6 (2012) 179-92.

[11] M.R. Buckley, J.P. Gleghorn, L.J. Bonassar, I. Cohen, Mapping the depth dependence of shear properties in articular cartilage, J. Biomech. 41 (2008) 24302437.

[12] T.J. Klein, J. Malda, R.L. Sah, D.W. Hutmacher, Tissue engineering of articular cartilage with biomimetic zones, Tissue Eng. Part B Rev. 15 (2009) 143-157.

[13] L.H. Nguyen, A.K. Kudva, N.L. Guckert, K.D. Linse, K. Roy, Unique biomaterial compositions direct bone marrow stem cells into specific chondrocytic phenotypes corresponding to the various zones of articular cartilage, Biomaterials 32 (2011) 1327-1338.

[14] T.J. Klein, M. Chaudhry, W.C. Bae, R.L. Sah, Depth-dependent biomechanical and biochemical properties of fetal, newborn, and tissue-engineered articular cartilage, J. Biomech. 40 (2007) 182-190. 
[15] P.J. Yang, J.S. Temenoff, Engineering orthopedic tissue interfaces, Tissue Eng. Part B Rev. 15 (2009) 127-141.

[16] R.M. Schinagl, D. Gurskis, A.C. Chen, R.L. Sah, Depth-dependent confined compression modulus of full-thickness bovine articular cartilage, J. Orthop. Res. 15 (1997) 499-506.

[17] J.M. Coburn, M. Gibson, S. Monagle, Z. Patterson, J.H. Elisseeff, Bioinspired nanofibers support chondrogenesis for articular cartilage repair, Proc. Natl. Acad. Sci. U. S. A. 109 (2012) 10012-10017.

[18] T. Karimi, D. Barati, O. Karaman, S. Moeinzadeh, E. Jabbari, A developmentally inspired combined mechanical and biochemical signaling approach on zonal lineage commitment of mesenchymal stem cells in articular cartilage regeneration, Integr. Biol. 7 (2015) 112-127.

[19] P.J. Verschure, J. VanMarle, L.A.B. Joosten, M.M.A. Helsen, F.P.J.G. Lafeber, W.B. VandenBerg, Localization of insulin-like growth factor-1 receptor in human normal and osteoarthritic cartilage in relation to proteoglycan synthesis and content, Br. J. Rheumatol. 35 (1996) 1044-1055.

[20] S.M. Zakaria, S.H. Sharif Zein, M.R. Othman, F. Yang, J.A. Jansen, Nanophase hydroxyapatite as a biomaterial in advanced hard tissue engineering: A review, Tissue Eng. Part B Rev. 19 (2013) 431-441.

[21] W.S. Toh, E.H. Lee, X.-M. Guo, J.K. Chan, C.H. Yeow, A.B. Choo, T. Cao, Cartilage repair using hyaluronan hydrogel-encapsulated human embryonic stem cellderived chondrogenic cells, Biomaterials 31 (2010) 6968-6980.

[22] I. Varga, R. Zamborský, D. Böhmer, The tissue engineering of articular cartilage: Cells, scaffolds and stimulating factors, Exp. Biol. Med. 237 (2012) 10-17.

[23] A.S. Sarvestani, E. Jabbari, Modeling and experimental investigation of rheological properties of injectable poly(lactide ethylene oxide fumarate)/hydroxyapatite nanocomposites, Biomacromolecules 7 (2006) 1573-1580.

[24] S. Moeinzadeh, D. Barati, X. He, E. Jabbari, Gelation characteristics and osteogenic differentiation of stromal cells in inert hydrolytically degradable micellar polyethylene glycol hydrogels, Biomacromolecules 13 (2012) 2073-2086.

[25] S. Moeinzadeh, S.N. Khorasani, J. Ma, X. He, E. Jabbari, Synthesis and gelation characteristics of photo-crosslinkable star poly(ethylene oxide-co-lactide-glycolide acrylate) macromonomers, Polymer 52 (2011) 3887-3896.

[26] X. He, J. Ma, E. Jabbari, Effect of grafting rgd and BMP-2 protein-derived peptides to a hydrogel substrate on osteogenic differentiation of marrow stromal cells, Langmuir 24 (2008) 12508-12516.

[27] J. Ma, X. He, E. Jabbari, Osteogenic differentiation of marrow stromal cells on random and aligned electrospun poly(L-lactide) nanofibers, Ann. Biomed. Eng. 39 (2011) 14-25.

[28] C.H. Lee, J.L. Cook, A. Mendelson, E.K. Moioli, H. Yao, J.J. Mao, Regeneration of the articular surface of the rabbit synovial joint by cell homing: A proof of concept study, Lancet 376 (2010) 440-448. 
[29] Stockwel.Ra, Interrelationship of cell density and cartilage thickness in mammalian articular cartilage, J. Anat. 109 (1971) 411-\&.

[30] L. Gao, T.J. Sheu, Y.F. Dong, D.M. Hoak, M.J. Zuscik, E.M. Schwarz, M.J. Hilton, R.J. O'Keefe, J.H. Jonason, TAK1 regulates SOX9 expression in chondrocytes and is essential for postnatal development of the growth plate and articular cartilages, J. Cell Sci. 126 (2013) 5704-5713.

[31] T.Y. Hui, K.M.C. Cheung, W.L. Cheung, D. Chan, B.P. Chan, In vitro chondrogenic differentiation of human mesenchymal stem cells in collagen microspheres: Influence of cell seeding density and collagen concentration, Biomaterials 29 (2008) 3201-3212.

[32] J.A. Henderson, X. He, E. Jabbari, Concurrent differentiation of marrow stromal cells to osteogenic and vasculogenic lineages, Macromol. Biosci. 8 (2008) 499-507.

[33] J.R. Taylor, An introduction to error analysis: The study of uncertainties in physical measurements, 2nd ed, University Science Books, Sausalito, CA (1997).

[34] A. Cuellar, A.H. Reddi, Stimulation of superficial zone protein/lubricin/PRG4 by transforming growth factor- $\beta$ in superficial zone articular chondrocytes and modulation by glycosaminoglycans, Tissue Eng. Part A 21 (2014) 1973-1981.

[35] C.P. Neu, A. Khalafi, K. Komvopoulos, T.M. Schmid, A.H. Reddi, Mechanotransduction of bovine articular cartilage superficial zone protein by transforming growth factor $\beta$ signaling, Arthritis Rheum. 56 (2007) 3706-3714.

[36] A. Khalafi, T.M. Schmid, C. Neu, A.H. Reddi, Increased accumulation of superficial zone protein (SZP) in articular cartilage in response to bone morphogenetic protein-7 and growth factors, J. Orthop. Res. 25 (2007) 293-303.

[37] T. Iwakura, R. Sakata, A.H. Reddi, Induction of chondrogenesis and expression of superficial zone protein in synovial explants with TGF-beta 1 and BMP-7, Tissue Eng. Part A 19 (2013) 2638-2644.

[38] L. Quintana, N.I.Z. Nieden, C.E. Semino, Morphogenetic and regulatory mechanisms during developmental chondrogenesis: New paradigms for cartilage tissue engineering, Tissue Eng. Part B Rev. 15 (2009) 29-41.

[39] A. Augello, C. De Bari, The regulation of differentiation in mesenchymal stem cells, Human Gene Ther. 21 (2010) 1226-1238.

[40] A. Woods, F. Beier, RhoA/Rock signaling regulates chondrogenesis in a contextdependent manner, J. Biol. Chem. 281 (2006) 13134-13140.

[41] N.S. Hwang, S. Varghese, H. Li, J. Elisseeff, Regulation of osteogenic and chondrogenic differentiation of mesenchymal stem cells in peg-ecm hydrogels, Cell Tissue Res. 344 (2011) 499-509.

[42] K.E. Kubow, S.K. Conrad, A.R. Horwitz, Matrix microarchitecture and myosin II determine adhesion in 3D matrices, Curr. Biol. 23 (2013) 1607-1619.

[43] J.K. Wise, A.L. Yarin, C.M. Megaridis, M. Cho, Chondrogenic differentiation of human mesenchymal stem cells on oriented nanofibrous scaffolds: Engineering the superficial zone of articular cartilage, Tissue Eng. Part A 15 (2008) 913-921. 
[44] O. Raabe, C. Reich, S. Wenisch, A. Hild, M. Burg-Roderfeld, H.-C. Siebert, S. Arnhold, Hydrolyzed fish collagen induced chondrogenic differentiation of equine adipose tissue-derived stromal cells, Histochem. Cell Biol. 134 (2010) 545-554.

[45] J.L. Allen, M.E. Cooke, T. Alliston, ECM stiffness primes the TGFbeta pathway to promote chondrocyte differentiation, Mol. Biol. Cell 23 (2012) 3731-3742.

[46] T. Fukumoto, J. Sperling, A. Sanyal, J. Fitzsimmons, G. Reinholz, C. Conover, S. O'driscoll, Combined effects of insulin-like growth factor-1 and transforming growth factor- $\beta 1$ on periosteal mesenchymal cells during chondrogenesis in vitro, Osteoarthritis Cartilage 11 (2003) 55-64.

[47] N. Indrawattana, G. Chen, M. Tadokoro, L.H. Shann, H. Ohgushi, T. Tateishi, J. Tanaka, A. Bunyaratvej, Growth factor combination for chondrogenic induction from human mesenchymal stem cell, Biochem. Biophys. Res. Commun. 320 (2004) 914-919.

[48] M.B. Mueller, R.S. Tuan, Functional characterization of hypertrophy in chondrogenesis of human mesenchymal stem cells, Arthritis Rheum. 58 (2008) 1377-1388.

[49] K. Chatterjee, S. Lin-Gibson, W.E. Wallace, S.H. Parekh, Y.J. Lee, M.T. Cicerone, M.F. Young, C.G. Simon, Jr., The effect of 3D hydrogel scaffold modulus on osteoblast differentiation and mineralization revealed by combinatorial screening, Biomaterials 31 (2010) 5051-5062.

[50] L.M. Bian, C. Hou, E. Tous, R. Rai, R.L. Mauck, J.A. Burdick, The influence of hyaluronic acid hydrogel crosslinking density and macromolecular diffusivity on human MSC chondrogenesis and hypertrophy, Biomaterials 34 (2013) 413-421. 


\section{Table Captions}

Table 1. Gel composition, nanofiber orientation and loading, in vitro gel degradation (mass loss), gel compressive modulus, growth factor concentrations, and hMSC cell density for hydrogel constructs simulating the superficial, middle, and calcified zones of articular cartilage.

Table 2. Effect of physicomechanical (matrix modulus and fiber) and biomolecular cues (TGF- $\beta 1$ and BMP-7) on percent normalized change in expression of superficial zone markers for hMSCs encapsulated in Superficial gel.

Table 3. Effect of physical (matrix modulus and fiber) and biomolecular cues (TGF- $\beta 1$ and IGF-1) on percent normalized change in expression of middle zone markers for hMSCs encapsulated in Middle gel.

Table 4. Effect of mechanical (matrix modulus+fiber) and biomolecular cues (TGF- $\beta 1$ and HA) on percent normalized change in expression of calcified zone markers for hMSCs encapsulated in Calcified gel.

\section{Figure Captions}

Figure 1. Schematic representation for the synthesis of hydrogel constructs simulating the superficial, middle, and calcified zones of articular cartilage. SPELA was synthesized by chain-extension of the hydrophilic 4-arm star PEG macromer (green) with degradable, short lactide segments (brown) followed by functionalization with a crosslinkable acrylate group at each chain-end (red). For Superficial gel, aligned fiber microsheets were dip-coated in SPELA10 gel precursor solution (SPELA, hMSCs, AcGRGD peptide), the dipped microsheets were laminated, UV crosslinked, and cultured with TGF- $\beta 1$ and BMP-7. For Middle gel, randomly-oriented fiber sheets were cut into small pieces, randomly dispersed in SPELA7.5 precursor solution, UV crosslinked, and cultured with TGF- $\beta 1$ and IGF-1. For Calcified gel, aligned fiber sheets were dip-coated in SPELA5 precursor solution, wrapped around a needle to simulate the vertical 
orientation of the fibers with respect to the chondral surface, UV crosslinked, and cultured with TGF- $\beta 1$ and HA.

Figure 2. Effect of TGF- $\beta 1$ on zone-specific chondrogenic expression of mRNA and biochemical markers for differentiating hMSCs. mRNA markers were SZP (a), Sox-9 (b), AGC (c), Col II (d), Col X (e), and ALP (f). Biochemical markers were total collagen (g), GAG (h), and ALP (i). hMSCs were encapsulated in L1 (red), L2 (blue), and L3 (green) gels simulating the superficial, middle, and calcified zones of articular cartilage, respectively, and cultured in chondrogenic medium with (solid lines) or without (dashed lines) TGF- $\beta 1$ without the addition of any other soluble growth factor. The pink, brown, and black diamonds show mRNA marker expression levels of hMSCs (day zero), chondrocytes, and pellet-cultured hMSCs (day 14), respectively, as controls. An asterisk represents a statistically significant difference $(\mathrm{P}<0.05)$ between the test group and all other groups for the given time point. The colored "+" sign represents a statistically significant $(\mathrm{P}<0.05)$ positive effect of TGF- $\beta 1$ on the zone corresponding to that color (red for superficial, blue for middle, and green for calcified) for all time points. The colored "_" sign represents a statistically significant $(\mathrm{P}<0.05)$ negative effect of TGF- $\beta 1$ on the specified zone for all time points. Error bars correspond to means \pm 1 SD for $n=3$.

Figure 3. Effect of TGF- $\beta 1$ on zone-specific protein expression and biochemical staining for differentiating hMSCs. Protein markers were SZP (a), AGC (b), Col II (c), and Col X (d). Bands in (e) are representative western blots corresponding to protein expressions in (a-d) as well as $\beta$-actin. Images in (f) are representative whole gel Alcian blue staining for the extent of GAG accumulation in each chondrogenic zone (L1, L2, L3) without and with TGF- $\beta 1$. Darkness and uniformity of the Alcian blue stain in the images in (f) qualitatively show the extent of sulfated GAG secretion by the encapsulated cells. Images in $(\mathrm{g})$ are representative whole gel Alizarin red staining for the extent of mineralization in the calcified zone (L3) without and with TGF- $\beta 1$ (L1 and L2 gels did not show significant staining for Alizarin red). Intensity of dark red staining in the images in (g) qualitatively shows the extent of mineral deposition by the encapsulated cells. hMSCs were encapsulated in L1 (red), L2 (blue), and L3 (green) gels simulating the superficial, middle, and calcified zones of articular cartilage, respectively, and cultured in chondrogenic medium with (solid lines) or without (dashed lines) TGF- $\beta 1$. 
An asterisk in $(\mathrm{a}-\mathrm{d})$ indicates a statistically significant difference $(\mathrm{P}<0.05)$ between the test group and all other groups for the given time point. The colored " + " sign in (a-d) represents a statistically significant $(\mathrm{P}<0.05)$ positive effect of TGF- $\beta 1$ on the zone corresponding to that color for all time points. The colored "_" sign in (a-d) represents a statistically significant $(\mathrm{P}<0.05)$ negative effect of TGF- $\beta 1$ on the specified zone for all time points. Error bars correspond to means $\pm 1 S D$ for $n=3$.

Figure 4. Effect of zone-specific growth factor (BMP-7 for superficial, IGF-1 for middle, and HA for calcified zone) on zone-specific chondrogenic expression of mRNA and biochemical markers for differentiating hMSCs. mRNA markers were SZP (a), Sox-9 (b), AGC (c), Col II (d), Col X (e), and ALP (f). Biochemical markers were total collagen (g), GAG (h), and ALP (i). hMSCs were encapsulated in L1 (red), L2 (blue), and L3 (green) gels simulating the superficial, middle, and calcified zones of articular cartilage, respectively, and cultured in chondrogenic medium with (solid lines) or without (dashed lines) the corresponding zone-specific growth factor. The pink, brown, and black diamonds show mRNA marker expression levels of hMSCs (day zero), chondrocytes, and pellet-cultured hMSCs (day 14), respectively, as controls. An asterisk represents a statistically significant difference $(\mathrm{P}<0.05)$ between the test group and all other groups for the given time point. The colored " + " sign represents a statistically significant $(\mathrm{P}<0.05)$ positive effect of the zone-specific growth factor on the zone corresponding to that color (red for superficial, blue for middle, and green for calcified) for all time points. The colored "-" sign represents a statistically significant $(\mathrm{P}<0.05)$ negative effect of the zone-specific growth factor on the specified zone for all time points. Error bars correspond to means $\pm 1 \mathrm{SD}$ for $\mathrm{n}=3$.

Figure 5. Effect of zone-specific growth factor (BMP-7 for superficial, IGF-1 for middle, and HA for calcified zone) on protein expression and biochemical staining for differentiating hMSCs. Protein markers were SZP (a), AGC (b), Col II (c), and Col X (d). Bands in (e) are representative western blots corresponding to protein expressions in (ad) as well as $\beta$-actin. Images in (f) are representative whole gel Alcian blue staining for the extent of GAG accumulation in each chondrogenic zone (L1, L2, L3) without and with the zone-specific growth factor. Darkness and uniformity of the Alcian blue stain in the images in (f) qualitatively show the extent of sulfated GAG secretion by the encapsulated cells. Images in $(\mathrm{g})$ are representative whole gel Alizarin red staining for 
the extent of mineralization in Calcified gel (L3) without and with the zone-specific growth factor (L1 and L2 gels did not show significant staining for Alizarin red). Intensity of dark red staining in the images in $(\mathrm{g})$ qualitatively shows the extent of mineral deposition by the encapsulated cells. hMSCs were encapsulated in L1 (red), L2 (blue), and L3 (green) gels simulating the superficial, middle, and calcified zones of articular cartilage, respectively, and cultured in chondrogenic medium with (solid lines) or without (dashed lines) the zone-specific growth factor. An asterisk in (a-d) indicates a statistically significant difference $(\mathrm{P}<0.05)$ between the test group and all other groups for the given time point. The colored " + " sign in (a-d) represents a statistically significant $(\mathrm{P}<0.05)$ positive effect of the zone-specific growth factor on the zone corresponding to that color for all time points. The colored "-" sign in (a-d) represents a statistically significant $(\mathrm{P}<0.05)$ negative effect of the zone-specific growth factor on the specified zone for all time points. Error bars correspond to means \pm 1 SD for $n=3$.

Figure 6. Effect of matrix modulus ( $80 \mathrm{kPa}$ for superficial, $2.1 \mathrm{MPa}$ for middle, and 320 $\mathrm{MPa}$ for calcified zone) on zone-specific chondrogenic expression of mRNA and biochemical markers for differentiating hMSCs. mRNA markers were SZP (a), Sox-9 (b), AGC (c), Col II (d), Col X (e), and ALP (f). Biochemical markers were total collagen (g), GAG (h), and ALP (i). hMSCs were encapsulated in L1 (red), L2 (blue), and L3 (green) gels simulating the superficial, middle, and calcified zones of articular cartilage, respectively, and cultured in chondrogenic medium with (solid lines) or without (dashed lines) the corresponding optimum matrix modulus. The "without" for L1 and L3 was the middle zone modulus of $2.1 \mathrm{MPa}$ which is the modulus typically used in cartilage regeneration experiments. Therefore, L2 did not have a "no opt mod" group in (a-i). The pink, brown, and black diamonds show mRNA marker expression levels of hMSCs (day zero), chondrocytes, and pellet-cultured hMSCs (day 14), respectively, as controls. An asterisk represents a statistically significant difference $(\mathrm{P}<0.05)$ between the test group and all other groups for the given time point. The colored "+" sign represents a statistically significant $(\mathrm{P}<0.05)$ positive effect of matrix modulus on the zone corresponding to that color (red for superficial, blue for middle, and green for calcified) for all time points. The colored "-" sign represents a statistically significant $(\mathrm{P}<0.05)$ negative effect of matrix modulus on the specified zone for all time points. Error bars correspond to means $\pm 1 \mathrm{SD}$ for $\mathrm{n}=3$. 
Figure 7. Effect of matrix stiffness ( $80 \mathrm{kPa}$ for superficial, $2.1 \mathrm{MPa}$ for middle, and 320 $\mathrm{MPa}$ for calcified zone) on protein expression and biochemical staining for differentiating hMSCs. Protein markers were SZP (a), AGC (b), Col II (c), and Col X (d). Bands in (e) are representative western blots corresponding to protein expressions in (ad) as well as $\beta$-actin. Images in (f) are representative whole gel Alcian blue staining for the extent of GAG accumulation in each chondrogenic zone (L1 and L3) without (no opt mod) and with (opt mod) the zone-specific matrix modulus. Darkness and uniformity of the Alcian blue stain in the images in (f) qualitatively show the extent of sulfated GAG secretion by the encapsulated cells. The "no opt mod" for L1 and L3 was the middle zone stiffness of 2.1 MPa. Therefore, L2 did not have a "no opt mod" group and no Alcian blue staining in (f). Images in (g) are representative whole gel Alizarin red staining for the extent of mineralization in Calcified gel (L3) without (no opt mod) and with (opt mod) the zone-specific modulus (L1 and L2 gels did not show significant staining for Alizarin red). Intensity of dark red staining in the images in (g) qualitatively shows the extent of mineral deposition by the encapsulated cells. hMSCs were encapsulated in L1 (red), L2 (blue), and L3 (green) gels simulating the superficial, middle, and calcified zones of articular cartilage, respectively, and cultured in chondrogenic medium with (solid lines) or without (dashed lines) the zone-specific matrix modulus (L2 did not have a "without" group). An asterisk in (a-d) indicates a statistically significant difference $(\mathrm{P}<0.05)$ between the test group and all other groups for the given time point. The colored " + " sign in (a-d) represents a statistically significant $(\mathrm{P}<0.05)$ positive effect of zone-specific matrix modulus on the zone corresponding to that color for all time points. The colored "-" sign in (a-d) represents a statistically significant $(\mathrm{P}<0.05)$ negative effect of matrix modulus on the specified zone for all time points. Error bars correspond to means \pm 1 SD for $n=3$.

Figure 8. Effect of nanofibers (horizontally, randomly, and perpendicularly aligned with respect to the gel surface) on zone-specific chondrogenic expression of mRNA and biochemical markers for differentiating hMSCs. mRNA markers were SZP (a), Sox-9 (b), AGC (c), Col II (d), Col X (e), and ALP (f). Biochemical markers were total collagen (g), GAG (h), and ALP (i). hMSCs were encapsulated in L1 (red), L2 (blue), and L3 (green) gels simulating the superficial, middle, and calcified zones of articular cartilage, respectively, and cultured in chondrogenic medium with (solid lines) or without (dashed lines) nanofibers. L3 gel did not have a "no fiber" group in (a-i) because fibers 
had to be added to Calcified gel to reach the matrix modulus of $320 \mathrm{MPa}$. The pink, brown, and black diamonds show mRNA marker expression levels of hMSCs (day zero), chondrocytes, and pellet-cultured hMSCs (day 14), respectively, as controls. An asterisk represents a statistically significant difference $(\mathrm{P}<0.05)$ between the test group and all other groups for the given time point. The colored "+" sign represents a statistically significant $(\mathrm{P}<0.05)$ positive effect of fibers on the zone corresponding to that color (red for superficial, blue for middle, and green for calcified) for all time points. The colored "-" sign represents a statistically significant $(\mathrm{P}<0.05)$ negative effect of fibers on the specified zone for all time points. Error bars correspond to means $\pm 1 \mathrm{SD}$ for $\mathrm{n}=3$.

Figure 9. Effect of nanofibers (horizontally, randomly, and perpendicularly aligned with respect to the gel surface) on protein expression and biochemical staining for differentiating hMSCs. Protein markers were SZP (a), AGC (b), Col II (c), and Col X (d). Bands in (e) are representative western blots corresponding to protein expressions in (ad) as well as $\beta$-actin. Images in (f) are representative whole gel Alcian blue staining for the extent of GAG accumulation in each chondrogenic zone (L1 and L2) without and with fibers. Darkness and uniformity of the Alcian blue stain in the images in (f) qualitatively show the extent of sulfated GAG secretion by the encapsulated cells. L3 gel did not have a "without" group and no Alcian blue or Alizarin red staining because fibers had to be added to Calcified gel to reach the matrix modulus of $320 \mathrm{MPa}$. hMSCs were encapsulated in L1 (red), L2 (blue), and L3 (green) gels simulating the superficial, middle, and calcified zones of articular cartilage, respectively, and cultured in chondrogenic medium with (solid lines) or without (dashed lines) fibers (L3 did not have a "no fiber" group). An asterisk in (a-d) indicates a statistically significant difference $(\mathrm{P}<0.05)$ between the test group and all other groups for the given time point. The colored " + " sign in $(\mathrm{a}-\mathrm{d})$ represents a statistically significant $(\mathrm{P}<0.05)$ positive effect of fibers on the zone corresponding to that color for all time points. The colored "-" sign in $(a-d)$ represents a statistically significant $(P<0.05)$ negative effect of fibers on the specified zone for all time points. Error bars correspond to means \pm 1 SD for $n=3$. 


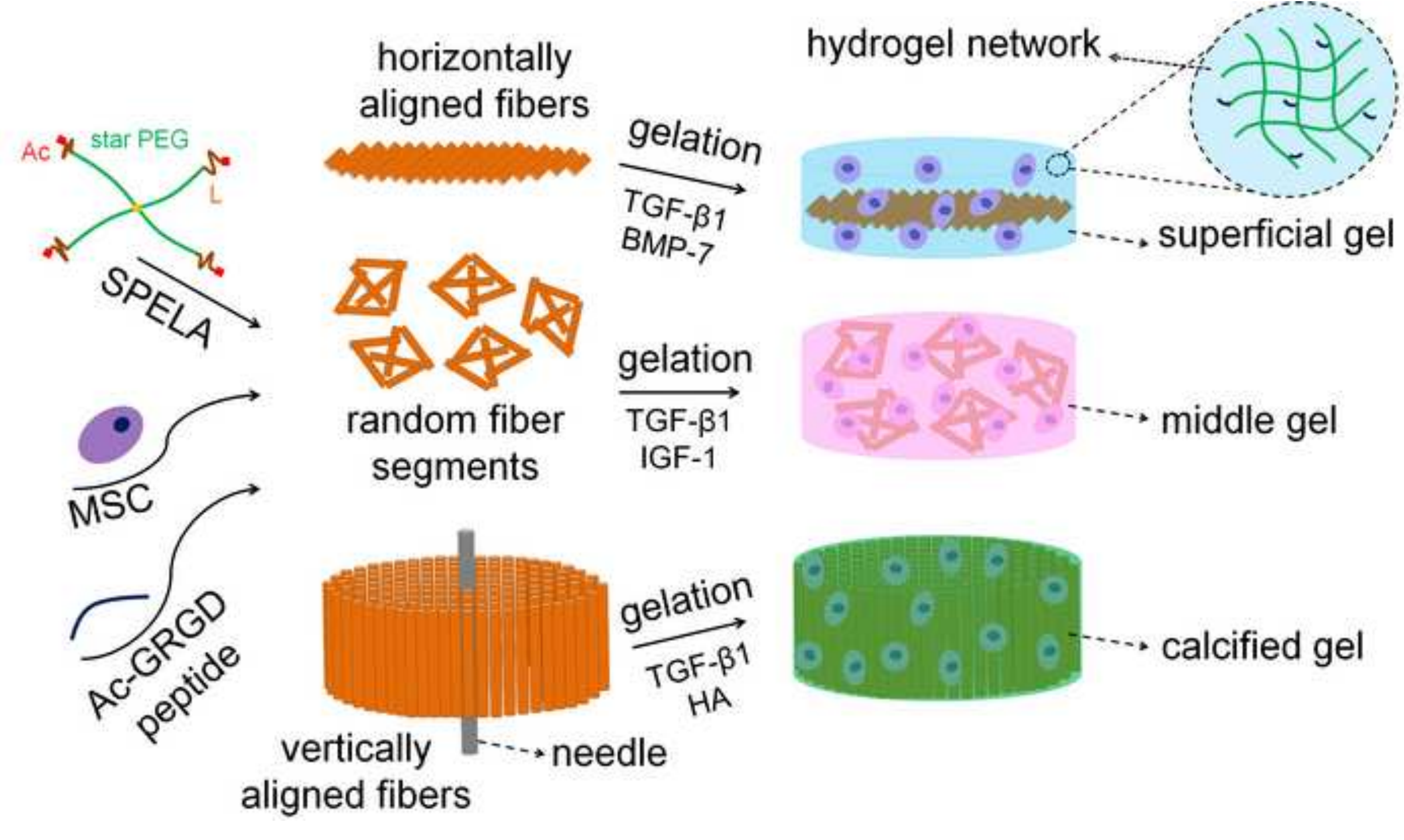



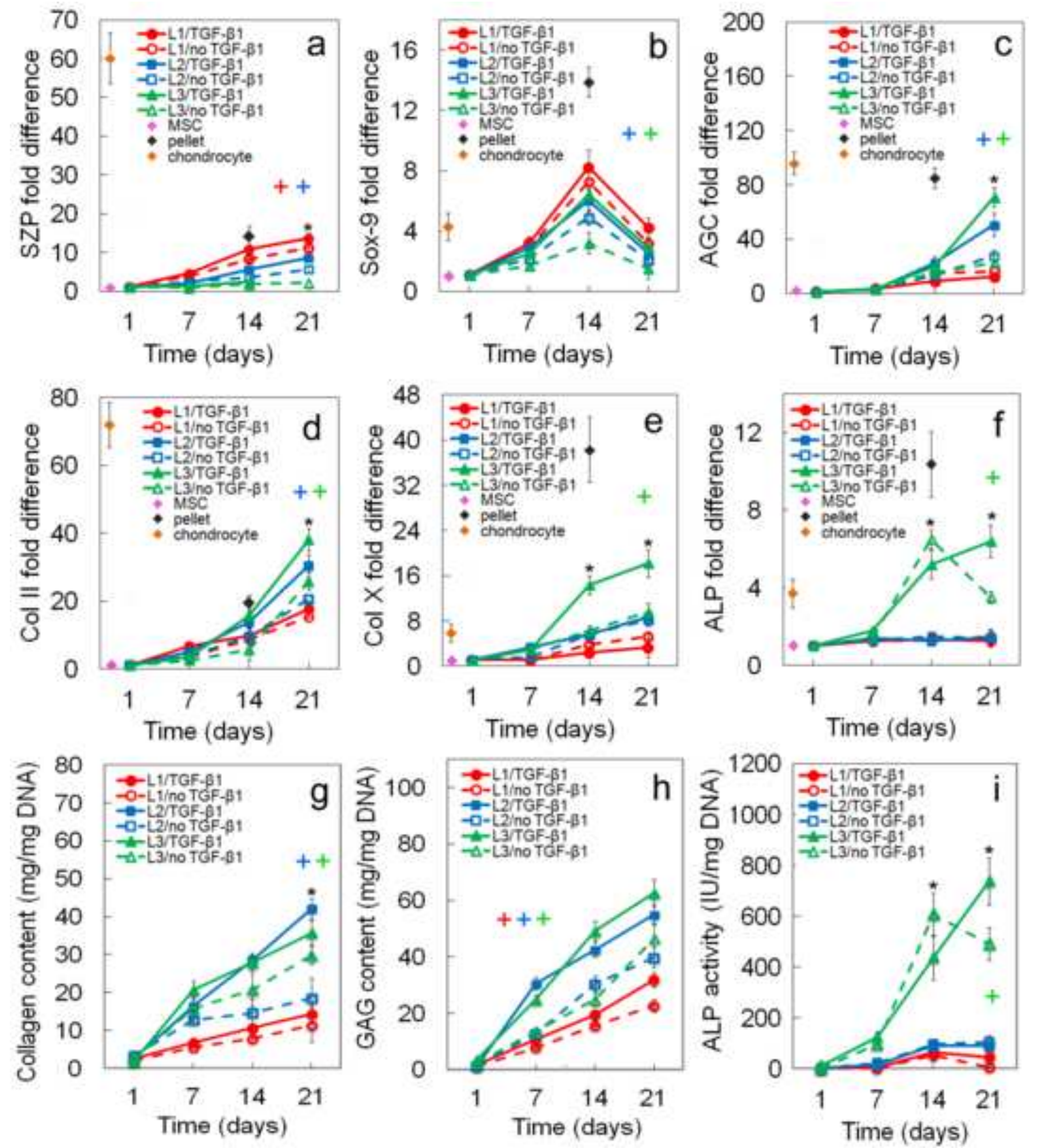

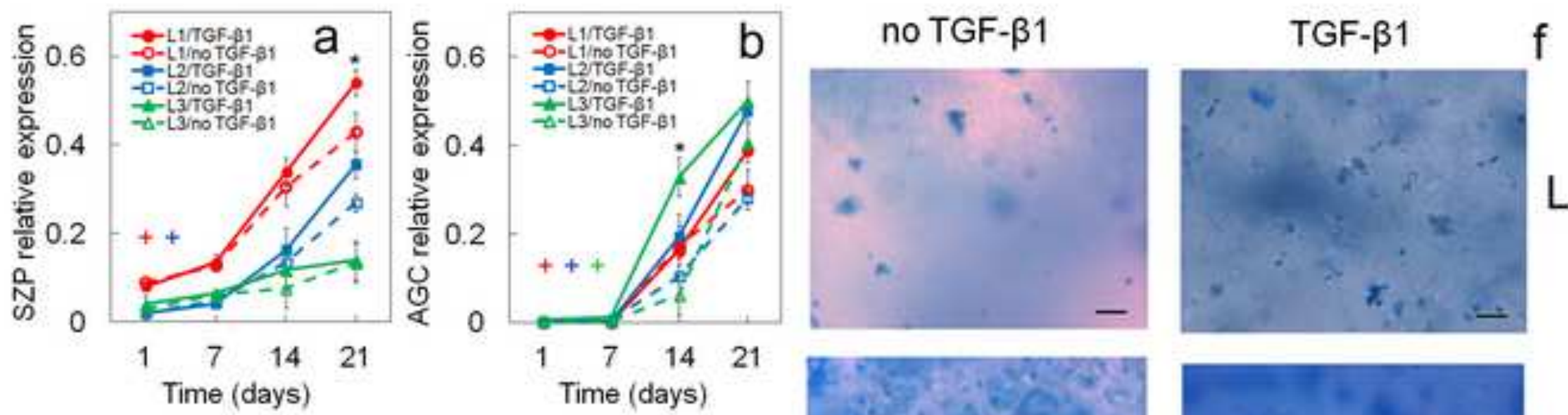

L1
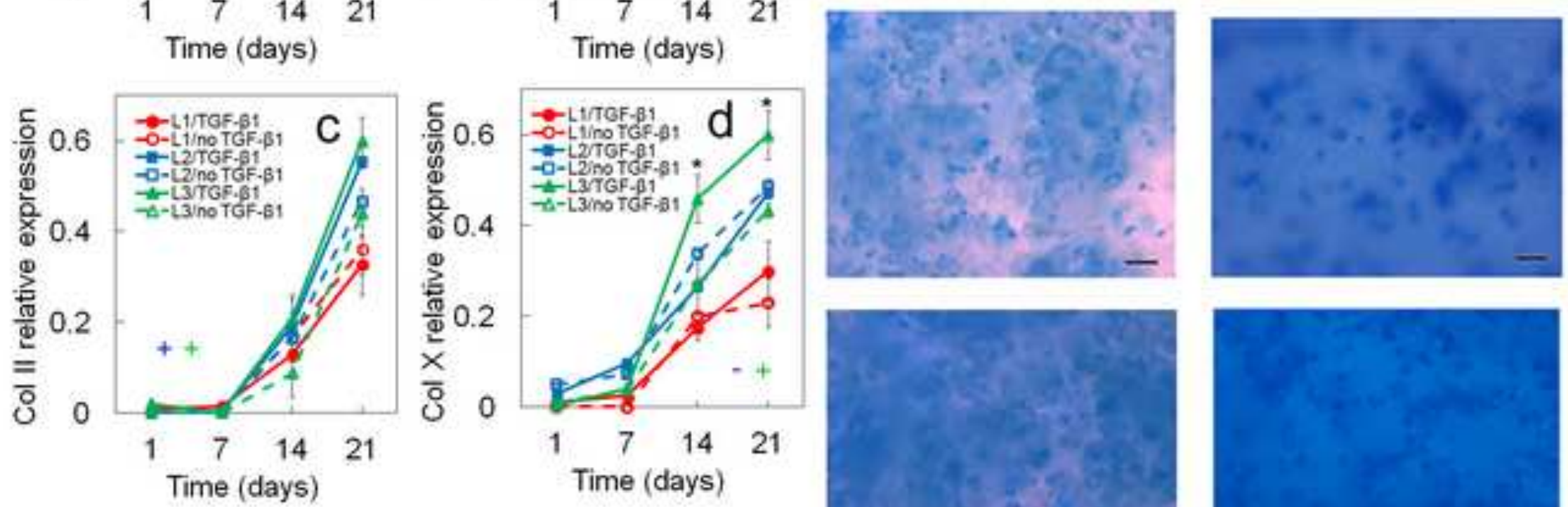

L2
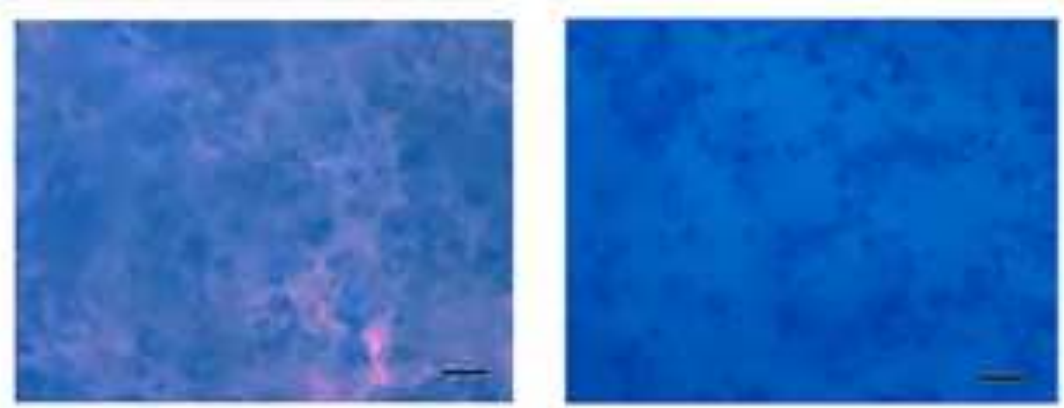

L3
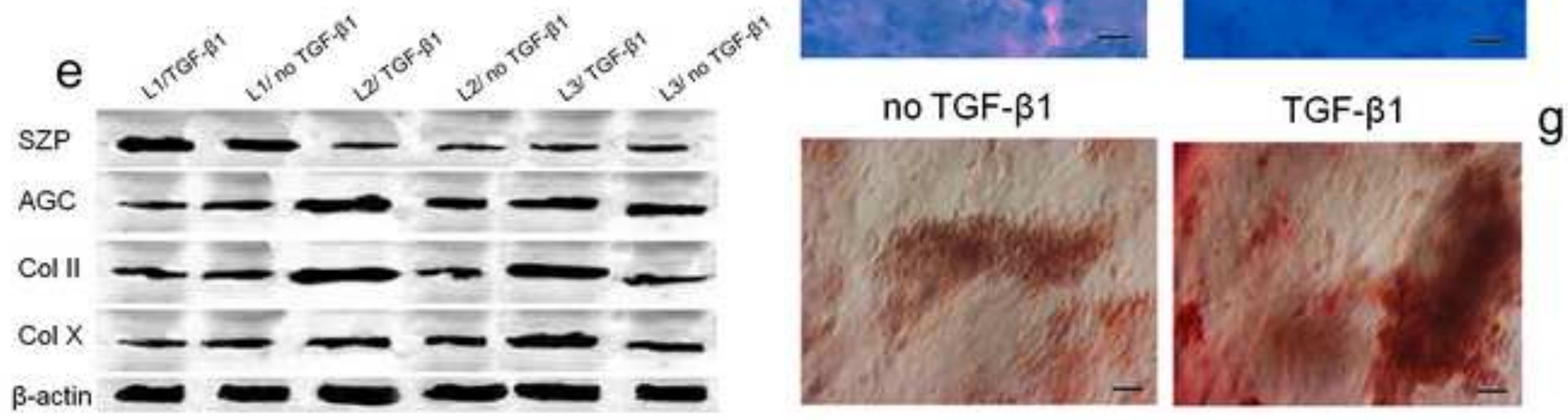

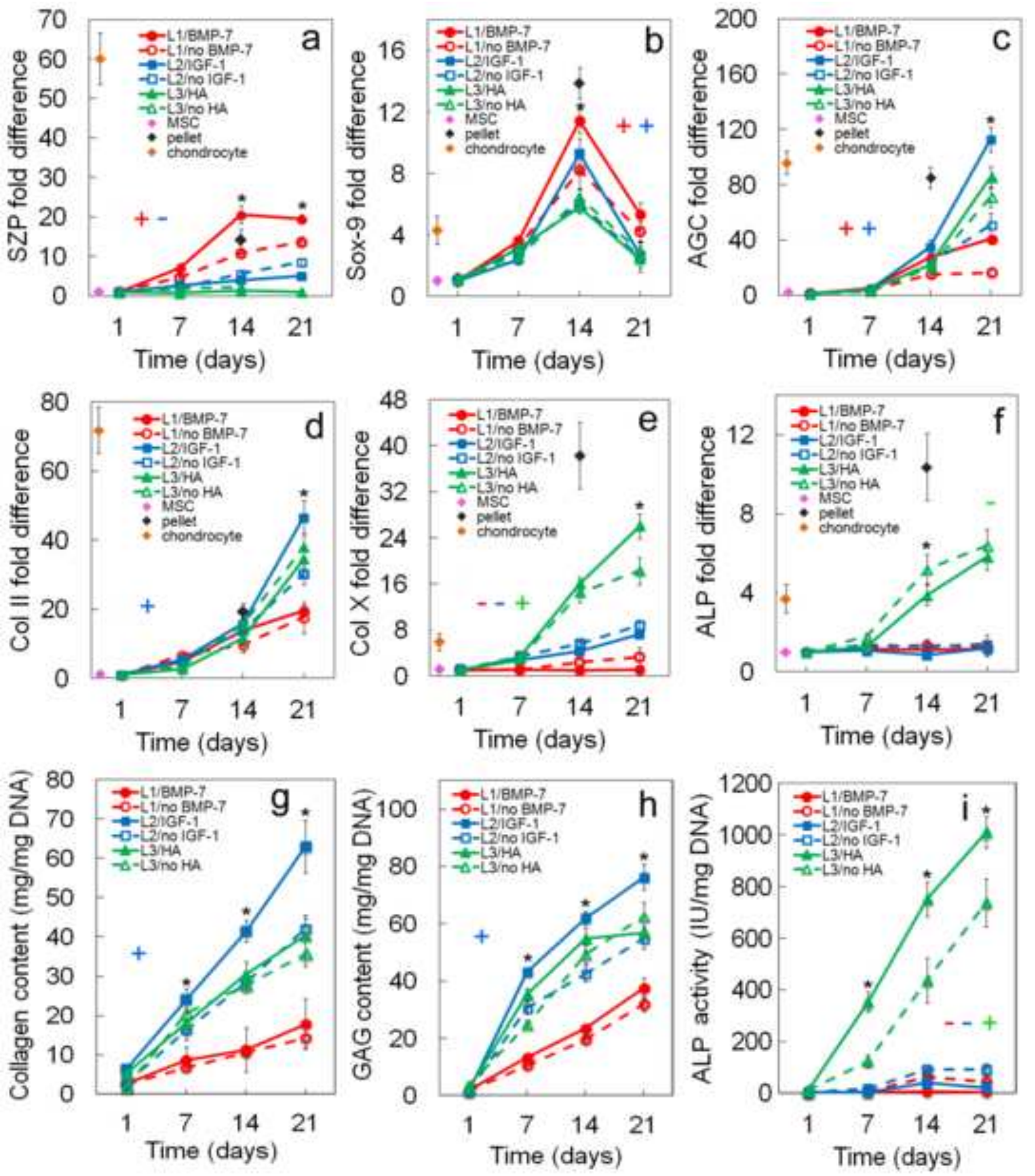

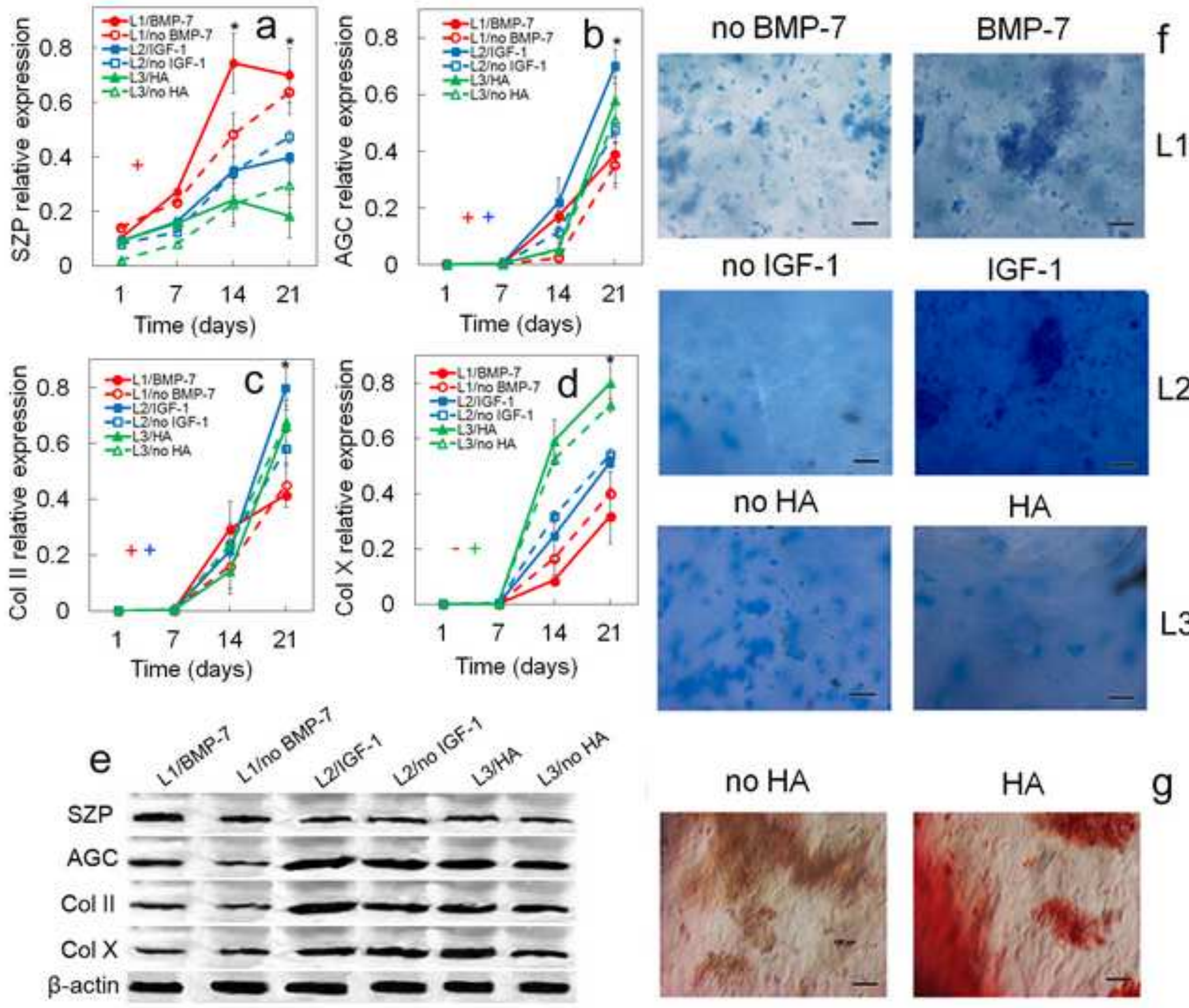

HA

g

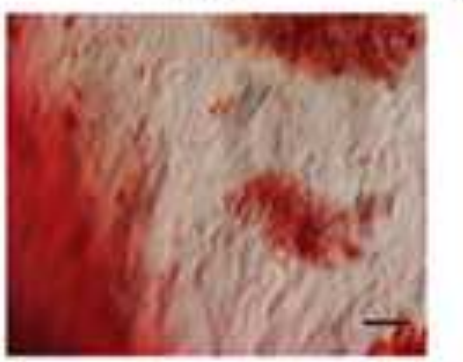



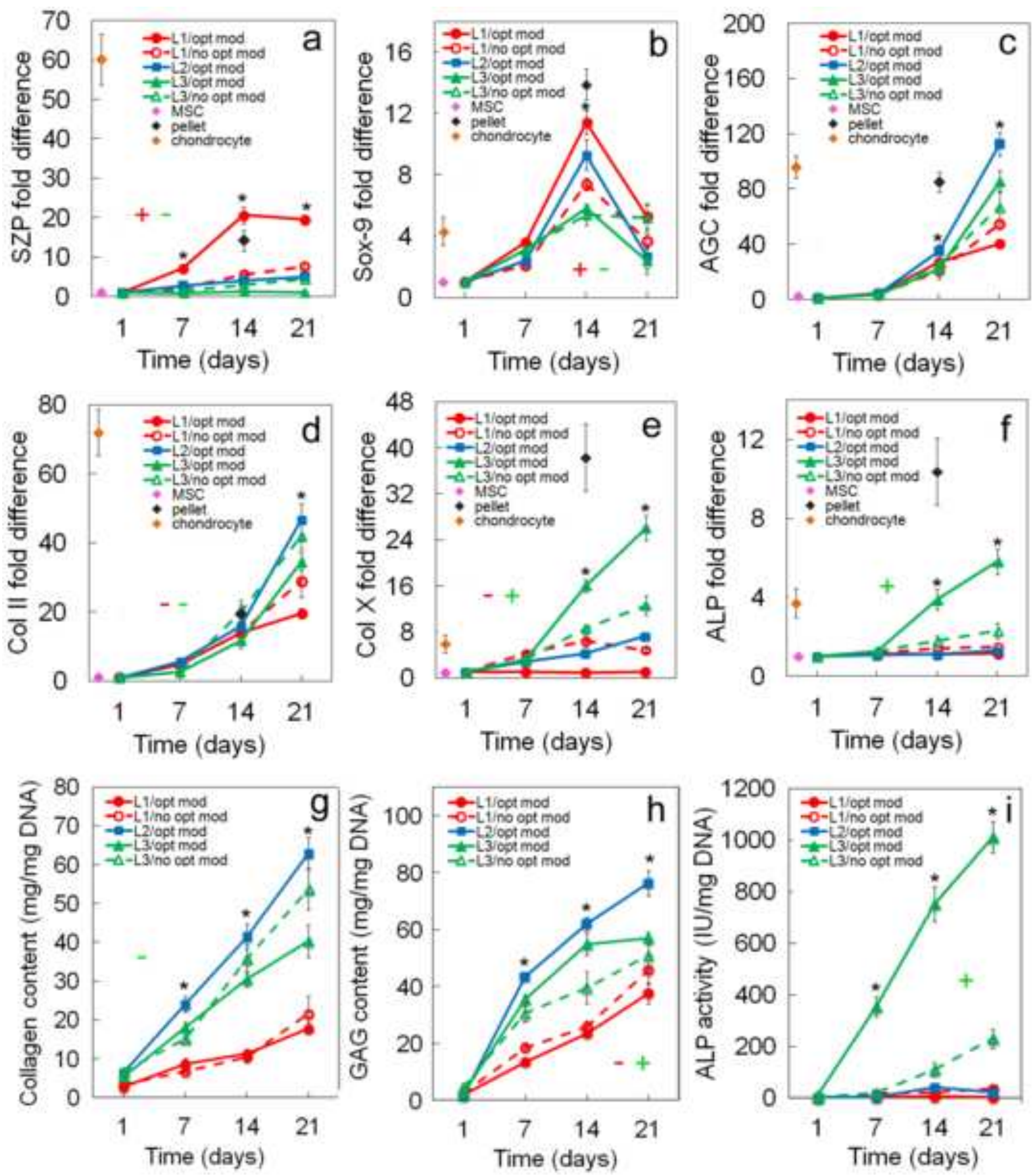

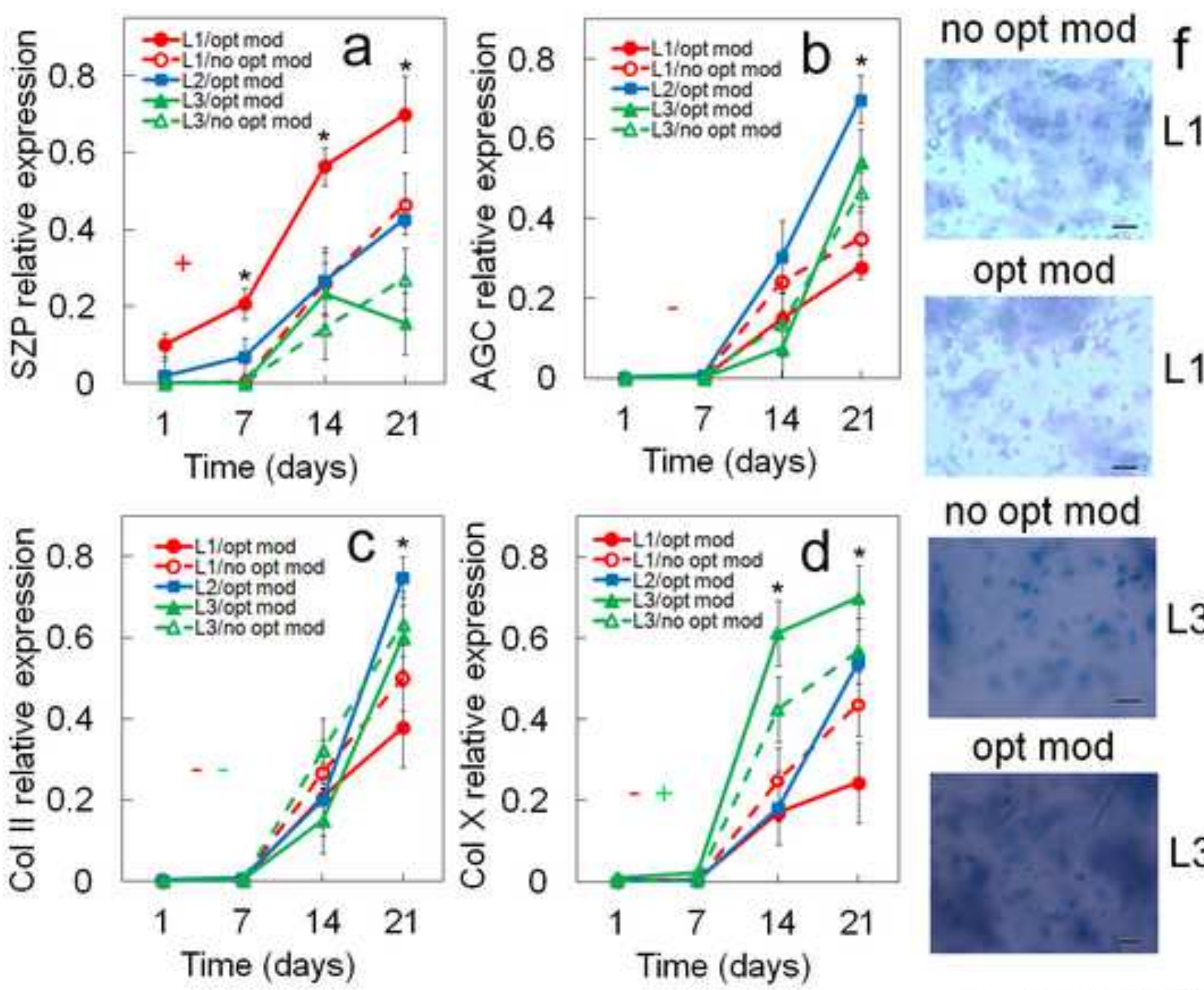

no opt mod
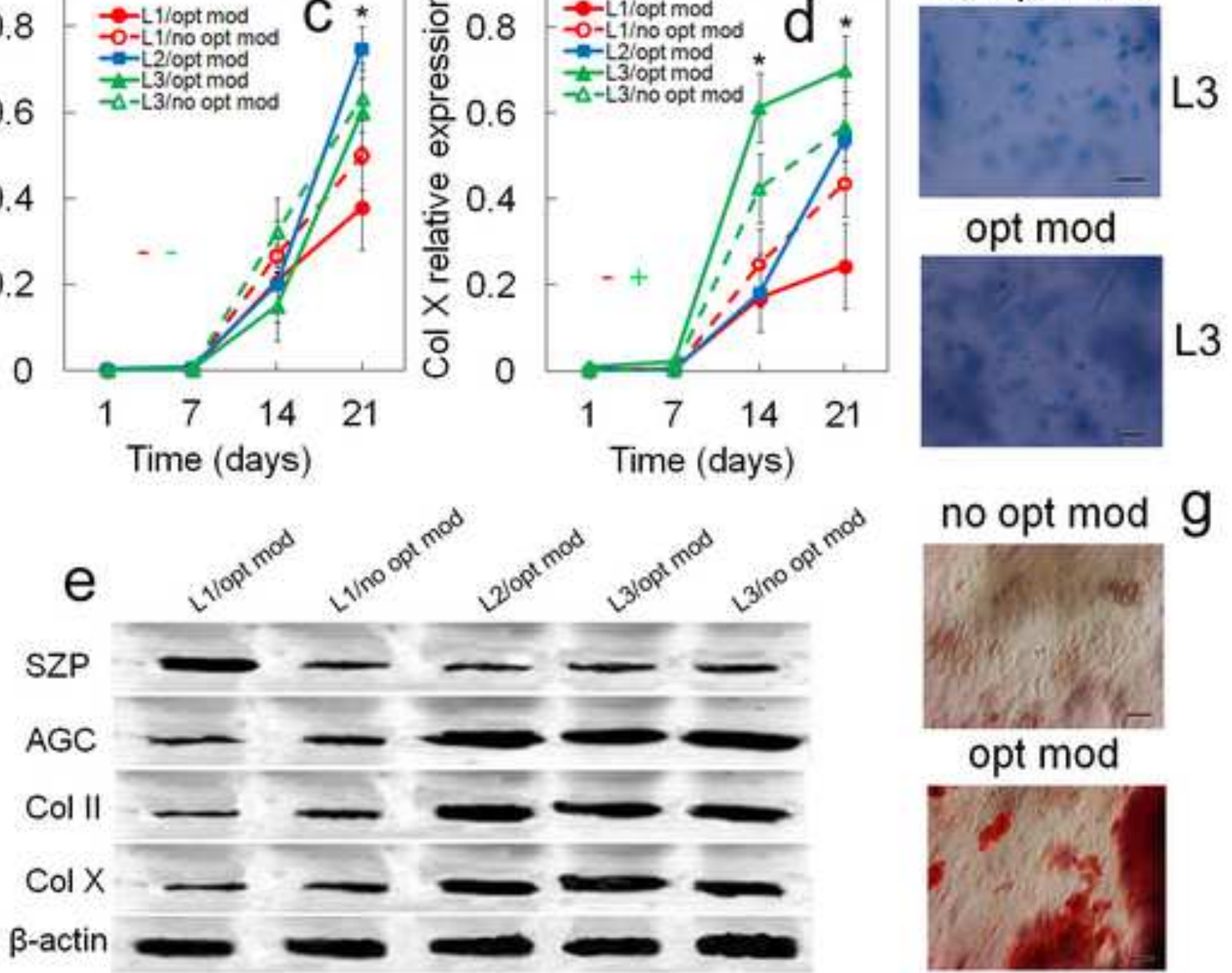

no opt mod
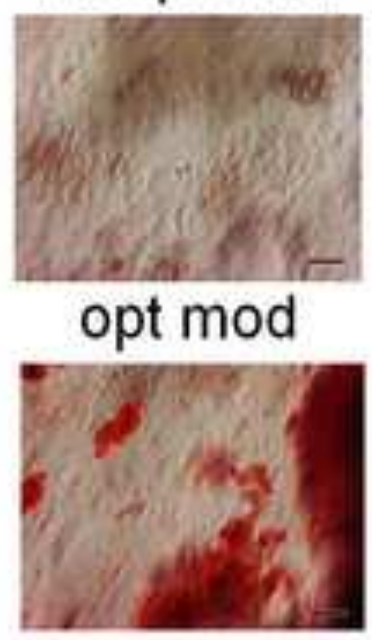

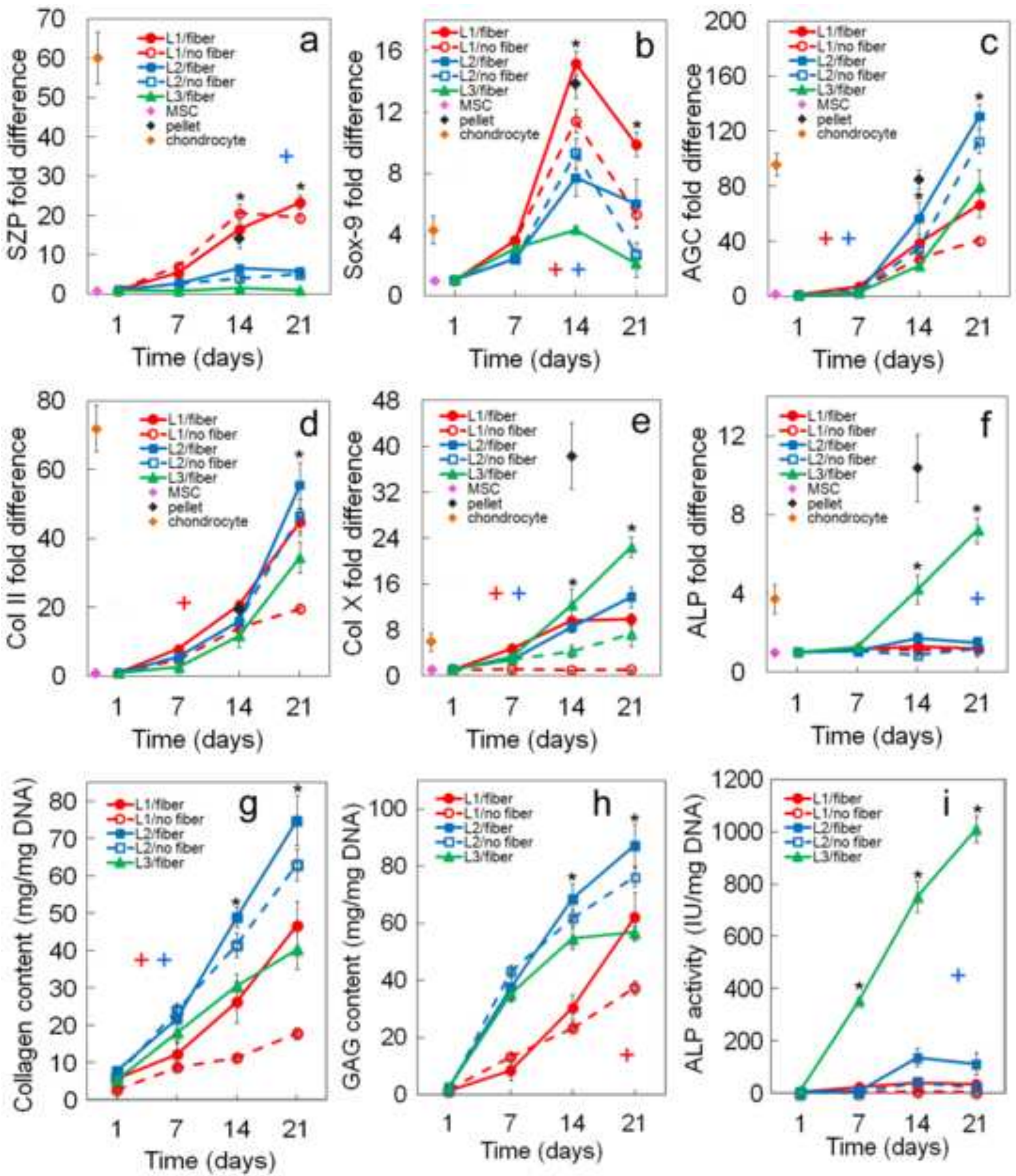

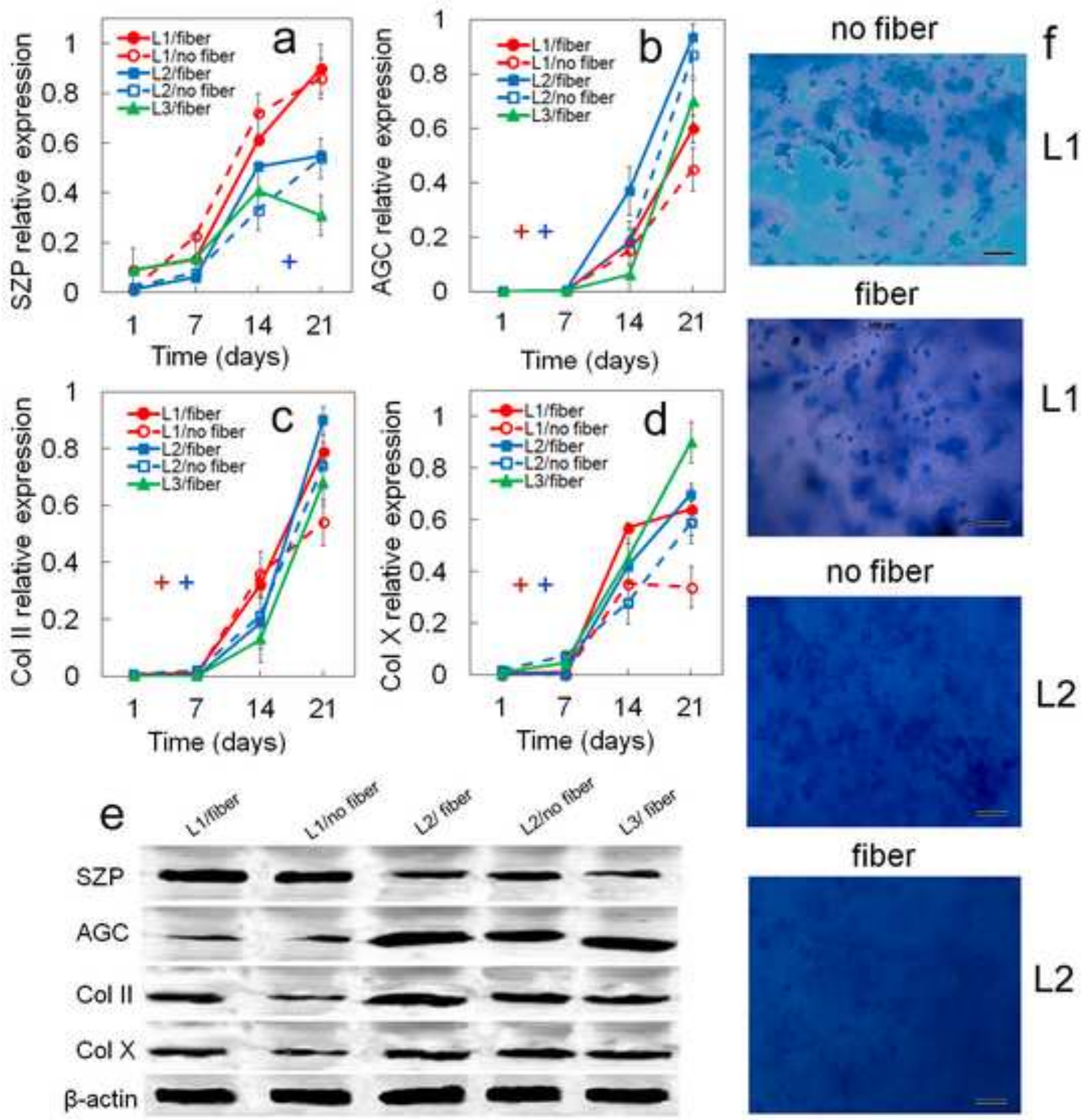